\title{
CAN QUANTITY REPLACE QUALITY? FOOD CHOICE, COMPENSATORY FEEDING, AND FITNESS OF MARINE MESOGRAZERS
}

\author{
Edwin CRUZ-Rivera ${ }^{1,3}$ AND Mark E. HaY ${ }^{2,4}$ \\ ${ }^{1}$ University of North Carolina at Chapel Hill, Institute of Marine Sciences, 3431 Arendell Street, Morehead City, \\ North Carolina 28557 USA \\ ${ }^{2}$ School of Biology, Georgia Institute of Technology, Atlanta, Georgia 30332-0230 USA
}

\begin{abstract}
Relationships among food choice, compensatory feeding, and the consequences for consumer fitness rarely have been quantified. We created foods of varying nutritional quality and evaluated the consequences of compensatory feeding for three sympatric species of amphipods by analyzing food choices, feeding rates, and long-term effects on fitness. Nutritional quality was manipulated by creating low-quality diets from algae (low in protein, nitrogen, and total organic carbon), high-quality diets from commercial fish food (high in protein, nitrogen, and total organic carbon), and intermediate-quality diets from mixtures of those two foods. When high- and low-quality diets were simultaneously offered, the more mobile, non-tube-building amphipods, Gammarus mucronatus and Elasmopus levis, both fed preferentially on the high-quality diet. The more sedentary, tube-building amphipod Ampithoe longimana did not discriminate between these foods. When confined to a single food type, all three species exhibited compensatory feeding on the low-quality diet. Despite compensatory feeding, when Elasmopus levis were cultured on the low-quality food, they experienced reduced survivorship, growth, and fecundity during two successive ovulations, compared to individuals feeding on more nutrient-rich foods. Low-nutrient foods caused similar declines in growth and female gonad size for Gammarus mucronatus. In contrast, the survivorship, growth, and fecundity of Ampithoe longimana was not affected by any of the diets tested. Thus, compensatory feeding allowed the more sedentary species, Ampithoe longimana, to completely circumvent the effects of low nutritional quality, but the same behavior was ineffective for both of the more mobile species, Gammarus mucronatus and Elasmopus levis. The ability of A. longimana to achieve equal fitness by substituting food quantity for food quality may allow this sedentary species to form longer associations with individual host plants, minimize movement among hosts, and thus lower its risk of being detected by predators.
\end{abstract}

Key words: amphipods; Ampithoe longimana; compensatory feeding; diet and fitness; Elasmopus levis; food choice and fitness of marine amphipods; Gammarus mucronatus; marine mesograzers; relative mobility and predation risk; nutrition.

\section{INTRODUCTION}

Investigations of how chemical, structural, morphological, or nutritional traits affect prey susceptibility to consumers are common (Hay and Fenical 1988, 1996, Duffy and Hay 1990, Harvell 1990, Fritz and Simms 1992, Hay and Steinberg 1992, Paul 1992, Rosenthal and Berenbaum 1992, Pawlik 1993, Hay 1996). It is rare, however, to demonstrate that these same traits actually affect consumer fitness, especially in marine systems (Hay 1996; but see Lindquist and Hay [1995]). Thus, for many marine consumers, the direct effects of prey traits on consumer fitness are poorly documented. Although low nutritional value often has been hypothesized to deter consumers (Feeney 1976, Moran and

Manuscript received 16 June 1998; revised 23 November 1998; accepted 8 December 1998.

${ }^{3}$ Present address: University of Guam Marine Lab, UOG Station, Mangilao, Guam 96913.

${ }^{4}$ Address correspondence to this author. E-mail: mark. hay@biology.gatech.edu
Hamilton 1980, Price et al. 1980, White 1993, Augner 1995), this hypothesis is controversial because consumers may compensate for low prey quality by consuming more, rather than less, prey tissue (Price et al. 1980).

Studies on the physiology and ecology of nutrition in humans, ruminants, insects, and other terrestrial animals have documented the impact of food quality on the feeding behavior and performance of consumers (Slansky and Scriber 1985, Slansky and Rodriguez 1987, Widdowson and Mathers 1992, Slansky 1993, Van Soest 1994), and have facilitated development of broadly applied theories, such as optimal foraging and optimal diet selection. In general, higher quality foods enhance fitness and should be selectively eaten when available (reviewed by Stephens and Krebs [1986]). Alternatively, some consumers actively mix different foods to achieve a more balanced diet, or to dilute detrimental chemicals that would accumulate to harmful concentrations if consumers fed extensively on one 
species of prey (Pennings et al. 1993, Bernays et al. 1994).

Consumers, however, may not always have access to high-quality or complementary foods, because natural enemies, competitors, or abiotic stresses limit consumer distribution and behavior (Sih 1987, Real and Caraco 1986, Huang and Sih 1991, Posey and Hines 1991, Stachowicz and Hay 1999b). When environmental constraints confine consumers to lower quality diets, consumers may still obtain sufficient nutrients, if they can compensate by increasing their consumption rate or assimilation efficiency (Simpson and Simpson 1990). Although compensation on lower quality foods has been observed for numerous consumers (Simpson and Simpson 1990, Rueda et al. 1991, Targett and Targett 1990, Graça et al. 1993, Pennings et al. 1993, Stachowicz and Hay 1996), few studies have evaluated how well compensatory feeding offsets the effects of low food quality on consumer fitness.

Several terrestrial studies of compensatory feeding have focused on small herbivores, such as insects and slugs (e.g., Slansky and Scriber 1985, Simpson and Simpson 1990, Rueda et al. 1991, Slansky 1993). Similar investigations of small marine herbivores (e.g., mesograzers such as amphipods, polychaetes, isopods, or small crabs, shrimps, and gastropods) are generally lacking. Because enemies or physical rigors limit the time or space over which mesograzers can forage (Lubchenco and Gaines 1981, Bernays and Graham 1988, Duffy and Hay 1991b, 1994), compensatory feeding might benefit mesograzers both directly (food acquisition) and indirectly (by reducing movement among hosts and thus lowering susceptibility to predation; Stachowicz and Hay 1996, 1999b).

In this paper, we evaluate whether compensatory feeding can circumvent the effects of low food quality on the survivorship, growth, or fecundity of three species of marine amphipods. Previous studies have suggested or shown that some amphipods consume a wide variety of foods in the field (Sanders et al. 1962, Nelson $1979 b$, Brawley 1992, DeLong et al. 1993), but the basic feeding ecology of most species is poorly known. This lack of information often has forced ecologists to assume that amphipods and other mesograzers can be pooled into a reasonably homogeneous trophic group (e.g., Moreno and Jara 1984, Paine 1992). Uncertainty about the validity of this assumption has stimulated debate regarding the potential effects of amphipod feeding within marine communities (Bell 1991, Duffy and Hay 1991a, Brawley 1992). This debate has focused, in part, on the notion that more sedentary, tubebuilding mesograzers will differ from more mobile species by minimizing their exposure to predation through selectively associating with, and feeding on, plants that are avoided by omnivorous fishes (Hay et al. 1987, 1988, Duffy and Hay 1991b, 1994, Sotka et al. 1999). Because of this emphasis, we chose to contrast the feeding of a more sedentary, tube-building species with two nontube-building species. Amphipods make good subjects for evaluating how feeding behaviors translate into effects on fitness, because they are direct developers (making it easy to count young or eggs), have short generation times, and can be cultured with relative ease.

Our experiments were designed to determine the relative effects of lower vs. higher quality diets on the feeding behavior and performance of three mesoconsumers that co-occur in coastal North Carolina, USA. We asked the following set of questions: (1) Which food does each species choose when presented with foods of different quality? (2) Do the amphipods exhibit compensatory feeding? (3) How do foods of different quality affect amphipod fitness? (4) Are food choice, compensatory feeding, and performance of the amphipods on different diets correlated?

\section{Methods \\ Organisms used}

Amphipods are one of the most common groups of mesograzers in temperate marine environments, with densities often reaching several thousand individuals per square meter (Brawley 1992). They are important secondary producers (Carrasco and Arcos 1984, Highsmith and Coyle 1990, Sarvala and Uitto 1991) and food sources for a variety of marine predators (Stoner 1979, Moreno and Jara 1984, Hines et al. 1990, Grebmeier and Harrison 1992, Shaffer et al. 1995, Beare and Moore 1997). The species studied, Ampithoe longimana, Elasmopus levis, and Gammarus mucronatus, consume a variety of foods, are broadly distributed along the Atlantic coast of the United States, and belong to three different families of gammaridean amphipods (Bousfield 1973).

The ecology and feeding habits of Ampithoe longimana are better known than for the other amphipod species. A. longimana is a relatively sedentary tubebuilding amphipod that consumes red, brown, and green macroalgae as well as diatoms, detritus, and vascular plant material (Bousfield 1973, Nelson 1979b, Hay et al. 1987, Duffy and Hay 1991b, 1994). This amphipod also suppresses colonization of some sessile benthic invertebrates (J. E. Duffy and M. E. Hay, personal communication), apparently by consuming newly settled larvae. Additionally, Holmes (1901) reported that A. longimana consumed fish tissue. His account can be questioned, however, because his description of $A$. longimana does not fit with the present day understanding of the taxonomy of A. longimana (see Bousfield 1973). However, other species of Ampithoe are opportunistically predatory (Brawley and Adey 1981), so A. longimana could be as well.

Gammarus mucronatus and Elasmopus levis do not build tubes, and they are less sedentary than A. longimana (Duffy and Hay 1994). G. mucronatus is common among algal mats and foliose macroalgae. Gut 
content studies and food choice observations of Gammarus mucronatus (previously Carinogammarus mucronotus) indicate that it consumes diatoms, detritus, epiphytic algae, macroalgae (Sanders et al. 1962, Zimmerman et al. 1979, Duffy and Hay 1994), and potentially macrofauna (Fredette and Diaz 1986; E. CruzRivera, personal observation). Elasmopus levis is found on seagrasses (Stoner 1979, Lewis 1984), gastropod egg masses (Fox 1980), and macroalgae (Duffy 1989; J. D. Thomas, personal communication). Guts of E. levis contain copepods, detritus, and algal material (Nelson 1979b). Thus, all three amphipod species occur on seaweeds and appear to be generalist feeders that will encounter and consume a broad range of nutritionally diverse foods, including seaweeds, microalgae, detritus, and small animals.

Ampithoe longimana (family Ampithoidae) were obtained from cultures maintained in outdoor flowthrough mesocosms at the University of North Carolina at Chapel Hill's Institute of Marine Sciences, in Morehead City, North Carolina, USA $\left(34^{\circ} 42^{\prime} \mathrm{N}, 76^{\circ} 41^{\prime} \mathrm{W}\right)$. These 20-L mesocosms received unfiltered seawater from adjacent Bogue Sound and contained a mixture of brown and green algae (primarily Sargassum filipendula, Dictyota menstrualis, and Enteromorpha spp.) that were brought from the field and placed in these tanks approximately every two weeks. Addition of these undefaunated plants meant that A. longimana from field populations were being added to the cultures every two weeks. A. longimana, as well as other amphipods, also recruited from the field via the seawater inflow pipes. A. longimana attained high numbers in these mesocosms, providing a reliable supply of test animals at times of the year when predators often keep amphipod densities low in the field. Elasmopus levis (family Melitidae) and Gammarus mucronatus (family Gammaridae) were collected from both the mesocosms and from mixed-species algal mats (composed primarily of Polysiphonia and Chaetomorpha) growing in filtration ponds that are part of the laboratory's flowthrough seawater system. These ponds are cleaned every one to three months. Between cleanings, amphipods recruit from the adjacent sound via inflow pipes. Given generation times of $\sim 25-30+\mathrm{d}$ at warm temperatures (Duffy and Hay 1991b; also see Results), amphipods would experience approximately one to three generations between major disturbances that would necessitate recolonization from field populations. We thus assume that the amphipods from ponds are representative of field populations.

\section{Artificial diets and quantification of food consumption}

Foods of different nutritional qualities were created using a mixture of freeze-dried palatable algae from North Carolina (equal amounts of Enteromorpha sp., Ulva sp., Hypnea musciformis, and Gracilaria tikvahiae) and freeze-dried fish food flakes (Wardley Total
Marine Fish Food, Ancaster, Ontario, Canada) which consist of fish meal, fish protein concentrate, soybean meal, shrimp meal, wheat feed flour, feeding oatmeal, squid meal, crab meal, fish oil, dried kelp, marine algae, lecithin, plankton, spirulina, multivitamin supplement, natural and artificial coloring, ethoxyquin. These were finely ground in a coffee mill and stored at $-70^{\circ} \mathrm{C}$. To assure uniformity of foods throughout the experiments, our diets were always made from a single set of foods that we collected (algae) or purchased (fish food), lyophilized, ground, and froze at the start of the study. Artificial diets were made using the methods of Hay et al. $(1994,1998)$, in which the powdered basic food was fixed onto plastic screen mesh by binding the food and screen with an agar matrix. Once the agar containing the food solidified onto the screen, it was cut to make food strips of the desired length and width. As the amphipods fed, the small squares comprising the screen mesh strips were cleared of food. Feeding rates were then measured by counting the number of squares cleared by the amphipods per unit of time.

The concentration of the powdered food in all of our artificial diets was $0.1 \mathrm{~g}$ dry mass $/ \mathrm{mL}$ food. This ratio of dry mass/volume approximates that found in several local seaweeds (M. E. Hay, personal observation) and allows the agar to bind the food into a firm matrix. Because plant material is lower in protein and nitrogen content, and higher in refractory ash content, than the commercial fish food, we refer to the algal diet as low quality and to the fish food diet as high quality (this was confirmed by direct measurement; see Results). In addition to our basic low-quality (algae-only) and highquality (fish-food-only) diets, we created intermediatequality diets by mixing different ratios of algae and fish food. Diets were as follows: $100 \%$ algae/0\% fish food (1:0); $90 \%$ algae/10\% fish food (9:1); $75 \%$ algae/ $25 \%$ fish food (3:1); $50 \%$ algae/50\% fish food (1:1); and $0 \%$ algae/100\% fish food (0:1).

\section{Analysis of foods}

To establish the differences in quality among our experimental diets, we measured protein, nitrogen, and carbon contents of six samples taken from each of the foods. Protein content was determined by Bradford's method (Bradford 1976), using bovine albumin serum (Sigma; Saint Louis, Missouri, USA) as the standard. Absorbance of the samples at $595 \mathrm{~nm}$ was measured in a Milton Roy Spectronic 1201 spectrophotometer (Ivyland, Pennsylvania, USA). A summary of this method is given by Duffy and Hay $(1991 b)$. As with all crude measures of protein, the Bradford method measures some proteins better than others and is subject to some interfering substances; however, it has been judged one of the most robust tests for relative comparisons of protein content (Davis 1988). Its extensive use by previous investigators also facilitates comparisons of our foods with others.

Total organic carbon (TOC) and nitrogen were mea- 
sured by combustion in a Control Equipment Company CEC440 CHN elemental analyzer (Marietta, Georgia, USA). Temperature of the combustion furnace was $990^{\circ} \mathrm{C}$. This method is not subject to the potential ambiguities involved in colorimetric protein assays. It thus provides an independent assessment of nutritional quality.

\section{Feeding assays}

We studied the preferences of each amphipod species towards high- vs. low-quality foods, by giving each species a choice between the algal-only and the fishfood-only diets. For Ampithoe longimana, we placed five amphipods in each of 30 plastic containers holding equal amounts of the high- and low-quality foods. Food strips were removed the next day and feeding was measured as the number of mesh squares from which all food had been eaten. Two similar experiments were conducted using either five Elasmopus levis or four Gammarus mucronatus in each of 25 separate containers. Amphipods were not starved before any of these assays. In a few replicates (between one and three), no food was consumed after $26 \mathrm{~h}$; these replicates were omitted from analyses, because they provided no information on relative feeding choice.

We evaluated compensatory feeding by confining replicate groups of each amphipod species to the lowquality algal diet alone or to the high-quality fish food diet alone. Eighty replicate containers $(N=40$ for each treatment), holding four Ampithoe longimana each, were randomly given a food strip of either the algalonly or the fish-food-only diets. The amphipods were used within four hours of collection and allowed to feed for $24 \mathrm{~h}$ before we measured food consumption and added new food strips to each replicate. Any dead amphipods were removed and replaced. The replacement amphipods were surplus individuals collected along with the ones in the experimental replicates; these were kept separately in two reservoirs. One spare group was fed on the low-quality algal diet and the other on the high-quality fish food diet, from the moment the assays began, so that the replacement individuals would have been exposed to the same food for an equivalent amount of time as the dead individuals they replaced. These no-choice feeding experiments were run for four consecutive days, because compensatory feeding sometimes requires a period of adjustment to new foods (Stockhoff 1993). We conducted similar experiments using either four Gammarus or six Elasmopus in each of 30 replicate containers $(N=15$ for each food type).

\section{Long-term experiments}

Dietary effects on amphipod fitness were evaluated by culturing each amphipod species on foods of different quality. Ampithoe longimana were raised on all five diets, and on a starvation (i.e., no food) diet. Elasmopus levis and Gammarus mucronatus were raised on the 1:0,1:1, and $0: 1$ (algae : fish food) diets, and on a starvation diet. Separate experiments assessing the food value of agar alone demonstrated that all individuals from all three amphipod species died in 4-8 d when offered either no food or agar alone. Days to death never differed between treatments for a species (Fisher's exact test). Days to death of all individuals were as follows for starved and agar-fed treatments, respectively: A. longimana, $4 \mathrm{~d}$ and $4 \mathrm{~d} ;$ E. levis, $7 \mathrm{~d}$ and $8 \mathrm{~d}$; G. mucronatus, $5 \mathrm{~d}$ and $7 \mathrm{~d}(N=17$ for each treatment-species combination). Thus, the agar matrix used to imbed the basic foods for our experimental diets had no measurable nutritional value for these three amphipod species. The starved treatments from our longterm experiments provided information on baseline mortality rates for nonfeeding individuals of each species.

Amphipods for the long term experiments were obtained by placing individual ovigerous females in separate petri dishes and feeding them on algae for $10 \mathrm{~d}$ (Ampithoe) and $14 \mathrm{~d}$ (Elasmopus and Gammarus), until enough newborns were available for our assays. Offspring from each female were measured from the rostrum to the end of the last large coxa under a dissecting microscope at $50 \times$ power. Each amphipod was randomly assigned to one of the experimental treatments (i.e., one of the diets or the starvation treatment) and placed individually in a $60 \times 15 \mathrm{~mm}$ (diameter $\times$ height) petri dish. Ovigerous females of Elasmopus and Gammarus were more difficult to find, and they often produced fewer than the four offspring required to place one from each mother in each of the four separate treatments run on these two amphipod species. To maximize our sample size for these two species, we followed two procedures. First, offspring from two females producing fewer than four newborns were pooled, and four of these newborns were then assigned randomly to the treatments. Second, when Elasmopus or Gammarus females produced enough young, we used more than one newborn from the same mother in each treatment. In such cases, the siblings were distributed so that each treatment initially had the same number of replicate individuals from the same mother. For example, if a female produced eight newborns, each of the four treatments would have two randomly assigned siblings from that mother (each sibling in an individual petri dish). Twelve siblings from the same mother was our upper limit, resulting in three individuals from that mother being placed in each treatment. The initial number of replicates per treatment was 33 individuals for Ampithoe (from 33 mothers), 33 individuals for Elasmopus (from 27 mothers), and 32 individuals for Gammarus (from 13 mothers).

In order to efficiently process all Ampithoe replicates daily (for which we had six treatments), petri dishes from the same treatment were kept together in holding trays until day 20. At that point, the remaining replicates were interspersed until the end of the experiment. 
We controlled for possible microspatial differences in environmental conditions by changing the relative position of the trays everyday. For the remaining two amphipod species, the treatments were interspersed from day one. Food and water were replaced daily for all species, and the petri dishes were scrubbed every two days to minimize microbial growth.

We recorded the lifespan (in days), the length at death, and the age and size of the females at first and second ovulations. Growth rate was calculated by subtracting the initial length of the amphipod from its length at death and dividing this result by the number of days it lived after the beginning of the experiment. At their first ovulation, we anesthetized the females using a solution of $38 \mathrm{mg}$ of MS-222 (3-amino benzoic acidethylester; Sigma) in $100 \mathrm{~g}$ of seawater. Females were measured and the number of eggs counted. Survivorship of the females did not seem to be affected by anesthetic, measurement, or egg counting, and after placing females back in regular seawater, they recovered within a few minutes. However, because females that ovulated were anesthetized and manipulated differently than males, survivorship beyond ovulation could have been confounded by handling of the females. We therefore limited our analyses of survivorship in Ampithoe longimana and Elasmopus levis until the day at which the first female became ovigerous in any of the treatments. Gammarus mucronatus females never ovulated, and, for this species, our data represent the total of surviving amphipods at the day gonadal area was measured.

Our mortality data only included those amphipods observed dead. On occasion, we were unable to find an individual in a dish. Loss of these amphipods could have been the result of accidental loss while changing food and water or rapid microbial degradation following death. We sometimes observed dense populations of ciliates in our petri dishes and small dead amphipods were often found reduced to only an exoskeleton containing large numbers of these ciliates inside. Incidental loss of replicates was low for all treatments in all species (Ampithoe longimana, 6 of 198 replicates; Elasmopus levis, 11 of 132 replicates; and Gammarus mucronatus, 9 of 128 replicates, for all treatments combined). Upon reaching the second ovulation, females were fixed in formalin and measured. Eggs were obtained by beheading the females, and pushing the eggs out of the brood pouch with fine forceps. After counting the eggs and measuring their length and width, we calculated the volume of individual eggs using the formula for the volume of a spheroid. By summing individual egg volumes, we also calculated the mean clutch volume for each amphipod female.

The duration of each long-term experiment depended on the timing of egg production or gonadal development. For A. longimana, we stopped the assay at day 59 , when the last female ovulated for the second time. The long-term experiment using E. levis was termi- nated at day 55, even though some females had failed to produce a second clutch during that time. However, the effects of diet on Elasmopus egg production were already clear by day 55. G. mucronatus females never ovulated during the course of the experiment, but did develop gonadal masses. At day 42, Gammarus females were fixed and measured. Reproductive potential was approximated by measuring the length and width of the gonadal masses on both sides of the females. The body of this species is translucent, and the developing female gonads appear as a whitish and opaque mass stretching inside the paraeonal segments of the amphipod. The gonads taper at both ends, so they were treated as an ellipse, and the area was calculated. We refer to this as the gonadal load and consider it a relative measurement of potential fecundity. It is given as mean surface area of the gonads per side of the female's body.

The amount of food eaten daily by a single small amphipod is too small to measure accurately, so we estimated the likelihood that an amphipod was eating at a particular time by recording the frequency that each amphipod was found in direct contact with the food strip. As soon as all individuals were large enough to locate easily with the naked eye, observations were made once a day after the new food square was placed in the petri dish. Timing of the actual observation was haphazardly chosen each day. Making these observations at different times minimized the potential confounding effects of disturbance created by renewing the water and food of the amphipods, as well as any effects microbial colonization of the artificial foods might have had on the behavior of the amphipods. The number of times an amphipod was found in direct contact with its food was converted to a frequency, and amphipods with $<10$ observations were excluded because of the potential error involved in turning small numbers of observations into percentages.

Amphipods might have clung to food strips in our assays simply because they provided physical structures and a place to hide, rather than because they were feeding. However, all the strips had equal length and width, so differences in amphipod behavior among treatments should be a function of the food coating the strips. Although these observations can only provide an indirect indication of feeding, animals compensating for low-quality food by increasing consumption would be expected to spend more time in contact with their food.

\section{Statistical analyses}

Survivorship patterns from the long-term experiments were analyzed using $\chi^{2}$ tests. For Ampithoe and Elasmopus, both of which ovulated during the longterm assays, we report survivorship until the first female became ovigerous in any of the treatments. We took this conservative approach, because females were anesthetized at their first ovulation, and longevity could have been affected by this treatment (although we saw 
no indication of this). Because Ampithoe ovulated more rapidly than the other species, survivorship patterns were analyzed after $14 \mathrm{~d}$ in Ampithoe, but after 24 and $43 \mathrm{~d}$ in Elasmopus and Gammarus, respectively. To confirm that this temporal difference was not biasing our findings for Ampithoe relative to the other species, we also analyzed survivorship of Elasmopus and Gammarus at day 14. Additionally, for Ampithoe longimana (against which six treatments were tested), we also analyzed survivorship excluding the 9:1 and 3:1 (algae: fish food) diets, which were not tested against Gammarus and Elasmopus. By excluding these two treatments from the analysis, the number of contrasts for Ampithoe was equivalent to the number of contrasts for Gammarus and Elasmopus, correcting partially for possible differences in statistical power of the analyses due to different numbers of comparisons.

For all three amphipod species, many of the deaths during the first week of the experiments appeared to occur because the small amphipods got trapped in the surface tension. It is unclear whether this was caused by amphipods swimming up in the water to avoid the food, by dead amphipods floating to the surface, or by amphipods swimming to the surface and then being too small to break off the surface tension and eventually dying. The data presented in this paper include all recorded deaths, because analyses both excluding and including amphipods found dead in the surface showed similar patterns.

Growth data were analyzed using one-way ANOVA. When significant differences among treatments were found, the ANOVA was followed by a Tukey's honestly significant difference (hsd) test adapted for unequal sample sizes (Day and Quinn 1989). Individuals dying early in the assays grew minimally, if at all. Because measuring small growth increments in such small amphipods involves considerable error, we included only the animals that outlived those held in the treatment without food (i.e., the starved amphipods). In Elasmopus, a few of the starved individuals survived for an unusually long period, contrasting with the $100 \%$ mortality in 7-8 d that occurred in our assay of starved vs. agar-fed amphipods. Elasmopus dying before the day at which survivorship in the starved treatment dropped to $10 \%$ were not included. We chose this $10 \%$ "threshold" because the survivorship in the starvation treatment of Elasmopus dropped precipitously (consistent with what is expected of starved individuals) and leveled off with three individuals that survived for several weeks. For these longer lived individuals, we found that algal spores had settled and germinated in the petri dishes and that our light scrubbing of the dishes did not remove the algal filaments. Therefore, animals in these three dishes were not effectively starved. After removal of the algal spores, these amphipods died within a few days.

One-way ANOVA and Tukey's hsd tests were used to analyze clutch size, egg volume, clutch volume, days to first and second ovulations, growth and size of females at both ovulations, gonadal load (in Gammarus), and proportion of time spent in contact with the food strips. The proportion (percentage) of time in contact with the food was arcsine-transformed before analysis. We used Kruskal-Wallis tests, followed by Tukey-type multiple comparisons (Zar 1984) in those cases where the distributions of the data were not normal. $\chi^{2}$ analysis was used to compare the number of Elasmopus females ovulating on the different diets during the first and second ovulation periods. Food choice and nochoice experiments were analyzed with paired sample and unpaired $t$ tests (on each individual day), respectively. We additionally tested for differences in consumption among the four consecutive days of the nochoice experiments by running a repeated-measures ANOVA for each amphipod species, using diet and experimental day as factors. Because differences in clutch or gonad sizes among treatments could result from direct effects of the diets on gonad production or from indirect effects of diet on the size of females, we attempted to differentiate among these factors using multiple regressions. This was largely unsuccessful due to the small number of females ovulating in some treatments.

\section{RESULTS}

Food analysis

Nitrogen, total organic carbon (TOC), and protein concentrations rose significantly as fish food was increased and algal material decreased in our experimental diets (Fig. 1). The fish-food-only (0:1) diet had $21 \times$ more protein, three times more nitrogen, and two times more TOC than the algal-only (1:0) diet. Our diets spanned a considerable range of nutritional values.

\section{Feeding assays}

When offered simultaneous access to diets made from algae or fish food, Ampithoe longimana did not discriminate between the two diets $(P=0.697$, pairedsample $t$ test; Fig. 2). In contrast, Gammarus mucronatus and Elasmopus levis significantly preferred the higher quality over the lower quality diet $(P=0.026$ and $P=0.043$, respectively, paired-sample $t$ tests). Gammarus and Elasmopus, respectively, ate $\sim 8.5$ and $6 \times$ as much of the fish food diet as they did of the algal diet.

When confined on a single food type, all three amphipods consumed more of the algal-based than fishfood-based diet (Fig. 3), suggesting that each species compensated for the lower nutritional quality of the algal diet (Fig. 1) by increasing consumption of that food. The pattern of compensatory feeding changed minimally over the 4-d duration of the experiments (as analyzed with repeated-measures ANOVA). Only for G. mucronatus could we detect a significant interaction 

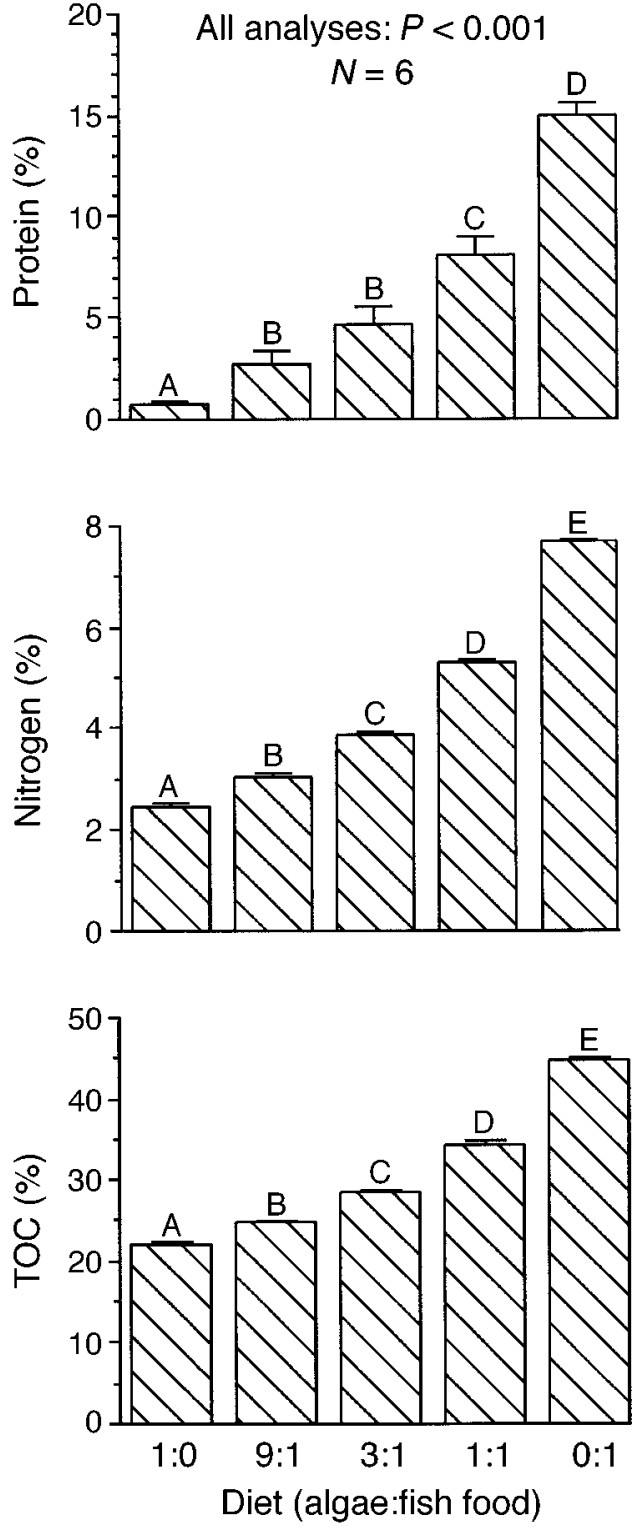

FIG. 1. Protein, nitrogen, and total organic carbon (TOC) content of experimental diets (mean percent dry mass +1 $\mathrm{SE})$. The analyses were made on subsamples taken from the homogenized batches of food. Error bars ( $+1 \mathrm{SE})$ thus represent methodological variance, rather than variance among independent samples. Analyses are by ANOVA followed by Tukey's hsd tests for groupings. Within each panel, statistically significant $(P<0.05)$ differences between means are indicated by different uppercase letters.

between experimental day and $\operatorname{diet}(P=0.037$; Table $1)$; on day three, these amphipods consumed less total food, and the difference in consumption between the two diets was not statistically significant (Fig. 3). There was a parallel decrease in total consumption on this same day for E. levis, although the difference in consumption between the two diets remained significant. Because our no-choice experiments with Gammarus and Elasmopus were run simultaneously in the same area, it is possible that temperature, or some other uncontrolled variable, caused these shifts in total consumption on different days. Overall consumption by $A$. longimana and E. levis differed among days $(P<0.001$ for both species, repeated-measures ANOVA; Table 1), but the patterns of compensatory feeding on the lower quality food were consistent and strong during the four consecutive days of the experiments (Fig. 3, Table 1).

\section{Long-term experiments}

The effects of diet on mesograzer fitness were assessed by culturing amphipods from juvenile through adult stages on different diets. Survivorship of A. longimana did not differ significantly among treatments cultured on any of the foods (Fig. 4), although the number of amphipods surviving did tend to decline as food quality diminished. Survival of the starved treatment declined to zero by day seven of the experiment, and was significantly lower than in all the fed treatments $\left(P<0.001, \chi^{2}\right.$ test; Fig. 4). Deletion of the 9:1 and 3:1 treatments, to make our number and type of treatment contrasts for A. longimana similar to those for G. mucronatus and E. levis, did not change the significant groupings.

Survivorship of both E. levis and G. mucronatus showed strong and significant treatment effects (Fig. 4 ), but the patterns differed markedly between the two species. E. levis survivorship was highest on the higher quality diets (the $0: 1$ and $1: 1$ algae: fish food diets), and significantly lower on the low-quality diet (1:0). In contrast, $G$. mucronatus survivorship was significantly suppressed on the highest quality diet (0:1) when compared to both the 1:1 and the 1:0 diets. In both Gammarus and Elasmopus, starved amphipods had significantly lower survivorship than any of the feeding treatments $\left(P<0.001\right.$ for both species; $\chi^{2}$ tests $)$. Data in Fig. 4 include those amphipods found dead on the surface tension (see Methods: Statistical analyses). If these amphipods were excluded from the analyses, neither the general patterns, nor the statistical differences among treatments changed. Additionally, for all three amphipod species, survivorship patterns did not change if only the males (which were not anesthetized) were used in the analyses.

Because Ampithoe longimana ovulated earlier than the other two species, we analyzed their survivorship patterns after $14 \mathrm{~d}$, and the other species after 24 (Elasmopus) or $43 \mathrm{~d}$ (Gammarus). We were concerned that analyzing survivorship of $A$. longimana after only 14 $\mathrm{d}$ could have diminished our ability to detect differences among treatments. However, the basic patterns of survivorship for G. mucronatus and E. levis were established early in these experiments. The $\chi^{2}$ analyses demonstrated that for Gammarus, the significant groupings seen at day 43 were established by day 16 of the experiment. For Elasmopus, significant groupings were established at day five. Thus, the among-species vari- 


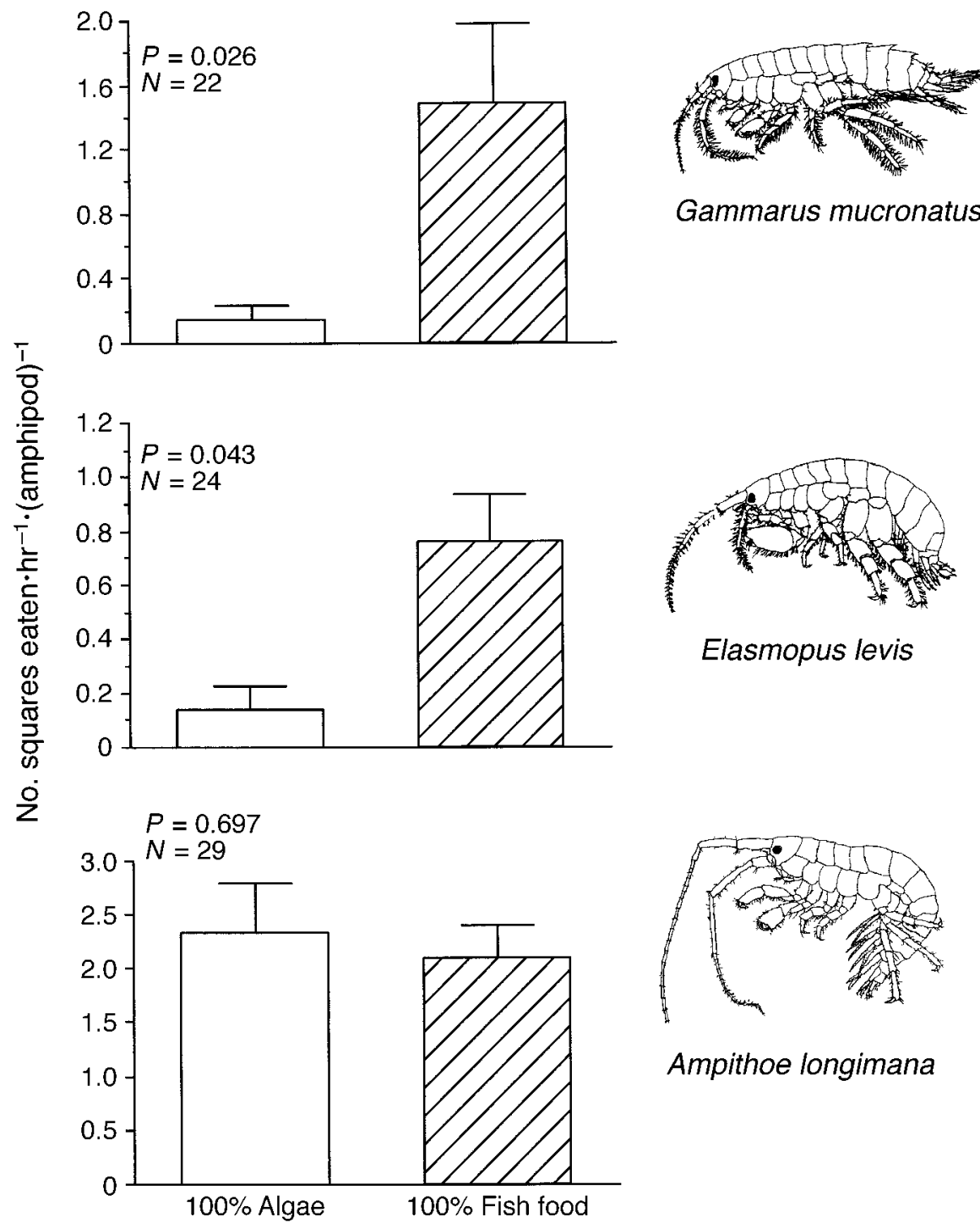

FIG. 2. Food choices of amphipods. Each replicate was simultaneously offered a choice between the algal-only and fishfood-only diets. Bars represent mean consumption $(+1 \mathrm{SE})$. Note that the $y$-axes have different scales. $P$ values are from two-tailed $t$ tests.

ation in survival on the experimental foods was due to differences among amphipod species and not the result of methodological differences in assay duration.

Diet had no effect on the growth rate of Ampithoe longimana ( $P=0.895$, one-way ANOVA; Fig. 5). In contrast, both Elasmopus levis and Gammarus mucronatus grew less on the algal-only diet $(P<0.001$ for both species, one-way ANOVA). These amphipods showed no differences in growth between the 1:1 and the 0:1 diets (Fig. 5).

Because we could not accurately measure food consumption by single amphipods in our long-term assays, we interpreted the frequency an amphipod was found on a food square as a crude indication of the time spent feeding. If amphipods on the lowest quality diet tried to compensate by feeding more (as suggested in Fig. 3 ), then we might expect amphipods to spend more time on low-quality diets than on high-quality diets. This general pattern occurred for each of the three species (Fig. 6). Ampithoe longimana spent more time in contact with the food strips than either of the other amphipod species, but the time decreased with increasing nutritional value of the food $(P<0.001$, one-way ANOVA; Fig. 6). For the other two amphipod species, time spent on the algal-only (1:0) diet was the inverse of growth on that diet. Both Gammarus and Elasmopus spent significantly more time on the 1:0 diet (Fig. 6), the food that suppressed growth (Fig. 5), than on the $1: 1$ or $0: 1$ diets. For these two amphipods, the $1: 1$ and $0: 1$ (algae : fish food) diets did not differ on their effects 


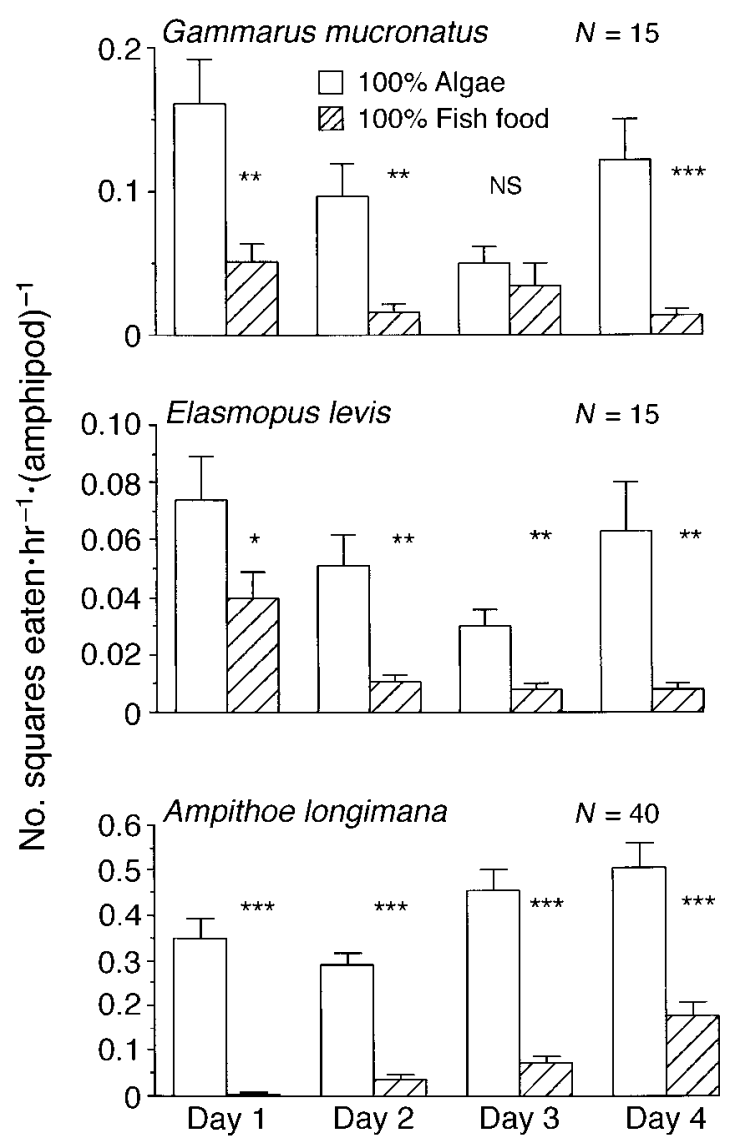

FIG. 3. Results from no-choice feeding assays (mean + $1 \mathrm{SE})$. Amphipods were offered either the algal-only or the fish-food-only diet, for four consecutive days. Note that the $y$-axes have different scales. Analyses were conducted using unpaired, two-tailed $t$ tests. Significance levels are as follows: $* P<0.05$; ** $P<0.01$; *** $P<0.001$.

on growth (Fig. 5), nor were differences detected in the time spent in contact with the foods (Fig. 6). These patterns, along with results from our no-choice feeding experiments (Fig. 3), support the hypothesis that all three species tried to compensate for lower quality diets by increasing the time they spent feeding. However, only Ampithoe appears to offset completely the cost of low-quality diets by using compensatory feeding (Figs. 4 and 5).

Consistent with this hypothesis, for Ampithoe longimana, diet had no effect on the percentage of ovulating females, number of days to ovulation, growth of females, clutch size, egg volume, or clutch volume (Figs. 7 and 8). In this species, all females became reproductive during both of the ovulation periods monitored. The single dietary effect we could detect for $A$. longimana was that females on the $1: 1$ food were slightly, but significantly, larger than females on the rest of the diets at the time of their second ovulation $(P=$ 0.009, one-way ANOVA; Fig. 7). Given the large number of contrasts made for Ampithoe, and the small magnitude of this difference, we are reluctant to interpret this one difference as meaningful.

In contrast to the lack of effects on Ampithoe, fecundity of Elasmopus levis and Gammarus mucronatus strongly decreased on the algal-only (1:0) food when compared to the fish-food-only (0:1) diet (Figs. 8-10). Fecundity on the mixed $(1: 1)$ diet was intermediate between these extremes. When fed on the 1:0 diet, both the proportion of Elasmopus females ovulating (Fig. 9) and the clutch volume (Fig. 8) were significantly less than on the 0:1 diet. Those females that ovulated on the algal-only diet also experienced significant reductions in growth and size (Fig. 9), relative to those on the mixed diet $(1: 1)$ or the fish-food-only $(0: 1)$ diet. Neither the days to first and second ovulations nor the mean volume of each individual egg were significantly affected by diet. Thus, the low-quality food constrained the number of females ovulating, the total volume of the clutch, and probably the clutch size (the number of females ovulating was so low on the algal diet, that our confidence in the data is limited; Fig. 9, bottom right histogram). However, for those females that did ovulate, neither the time to maturation nor the volume of individual eggs was affected. The most dramatic effect was on the percentage of females ovulating. Only

TABLE 1. Results from a repeated-measures ANOVA on the no-choice feeding experiments during the four consecutive days. Data are from Fig. 3.

\begin{tabular}{llrrr}
\hline \hline \multicolumn{1}{c}{ Species } & Factor & $F$ & df & $P$ \\
\hline Gammarus mucronatus & Diet & 34.866 & 1 & $<0.001$ \\
& Day & 4.275 & 3 & 0.004 \\
Elasmopus levis & Diet $\times$ Day & 2.692 & 3 & 0.037 \\
& Diet & 29.925 & 1 & $<0.001$ \\
Ampithoe longimana & Day $\times$ Day & 5.428 & 3 & $<0.001$ \\
& Diet $\times$ & 1.005 & 3 & 0.331 \\
& Diet & 179.79 & 1 & $<0.001$ \\
& Day & 11.805 & 3 & $<0.001$ \\
& Diet $\times$ Day & 1.216 & 3 & 0.358
\end{tabular}

Notes: This is an a posteriori test for detecting among-day differences in total consumption of food by the amphipods in the no-choice assays, and the interaction of among day differences with the two diets tested. The variable factor "diet" indicates differences in consumption between the algae-only and the fish-food-only diets, on each separate day. 


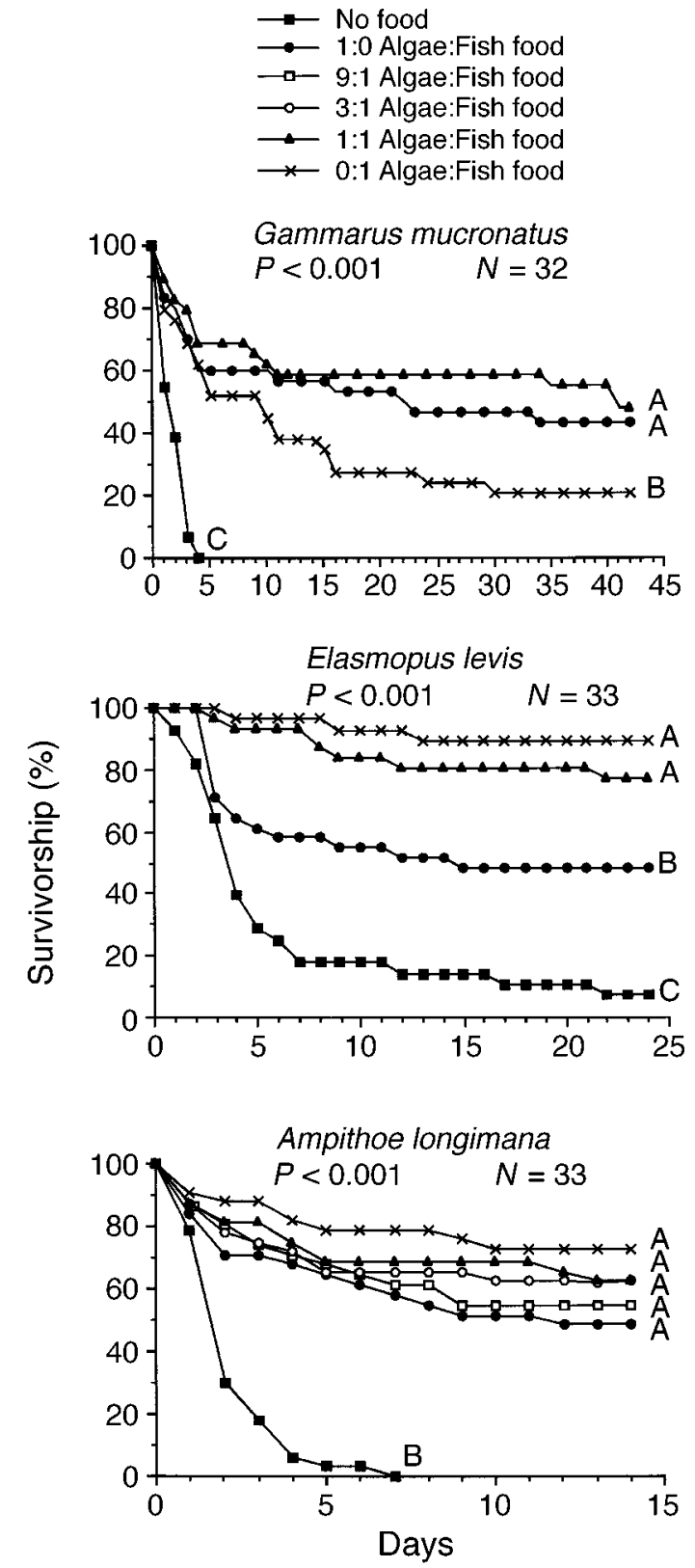

FIG. 4. Survivorship of amphipods on diets of different composition. Amphipods were monitored daily, but symbols from the survivorship plots for G. mucronatus are shown every two days to enhance clarity. $P$ values and significant groupings (indicated by uppercase letters) are from $\chi^{2}$ tests. Survivorship was analyzed when reproductive parameters were measured on the first female in each species. This corresponds to the last day for each figure. Note that this time period varied among species ( $x$-axis).

$33 \%$ of the Elasmopus females ovulated on the algalonly diet, compared with $93 \%$ and $100 \%$ on the $1: 1$ and fish-food-only diets, respectively $\left(P<0.001, \chi^{2}\right.$ test; Fig. 9, upper left histogram). The percentage of females reaching a second ovulation was lower for all three treatments, but the lowest number occurred for the poorest quality food $\left(P=0.028, \chi^{2}\right.$ test $)$.

For both A. longimana and E. levis, we qualitatively monitored the fate of the eggs in the first clutch. We observed that, while most unfertilized eggs appeared to be reabsorbed, some females of both species shed eggs either with old molts (still in the brood pouch), or released a few eggs individually on the petri dish. No diet-related differences were apparent for these qualitative observations.

The gonadal surface area of Gammarus mucronatus differed significantly among treatments. Gonad area at day 42 was significantly decreased on the algal-only (1:0) diet but equivalent on the other two treatments $(P<0.001$ for the one-way ANOVA; followed by Tukey's hsd tests; Fig. 10). This paralleled the patterns in female length on these same foods. Individuals raised on the 1:1 and 0:1 diets had gonadal areas approximately three times larger than those raised on the algal-only 1:0 diet.

Differences in clutch or gonadal sizes among treatments in E. levis and G. mucronatus could have resulted from the direct effects of diet quality on gonad production alone, or from constraints on growth that in turn affected fecundity. We attempted regression analyses to further investigate these possibilities, but the very small number of replicates in some treatments constrained statistical power so severely that these analyses were not useful. Nevertheless, if all females within each species were pooled together, there was a significant positive correlation between size of the females and size of the clutch or gonads for each of these two amphipod species $(P<0.001$ for $G$. mucronatus; $P=0.002$ for $E$. levis). However, while female size could account for $88 \%$ of the variance in G. mucronatus, it could explain $<30 \%$ in the case of E. levis, suggesting that size alone was an inadequate explanation for differences in fecundity among E. levis females.

To summarize, the low-quality algal-only diet had no effect on the measured components of fitness in Ampithoe, but it decreased fitness of Gammarus and Elasmopus. Conversely, the high-quality fish-foodonly diet and the 1:1 mixed (intermediate-quality) diet increased survivorship, growth, and reproductive output of Elasmopus. Results for Gammarus were less clear. The fish-food-only diet increased growth and reproductive potential, but significantly suppressed survivorship, relative to the algal-only diet or the $1: 1$ mixed diet. Performance on the 1:1 mixed diet was comparable to that on the fish-food-only diet for both Elasmopus and Gammarus (except for survivorship of Gammarus). For Ampithoe, performance on the three intermediate-quality mixed diets $(9: 1,3: 1$, and $1: 1)$ was equivalent to that on the algal-only and fish-food-only (1:0 and 0:1) diets, which comprised the lowest and highest quality foods offered to these amphipods. 

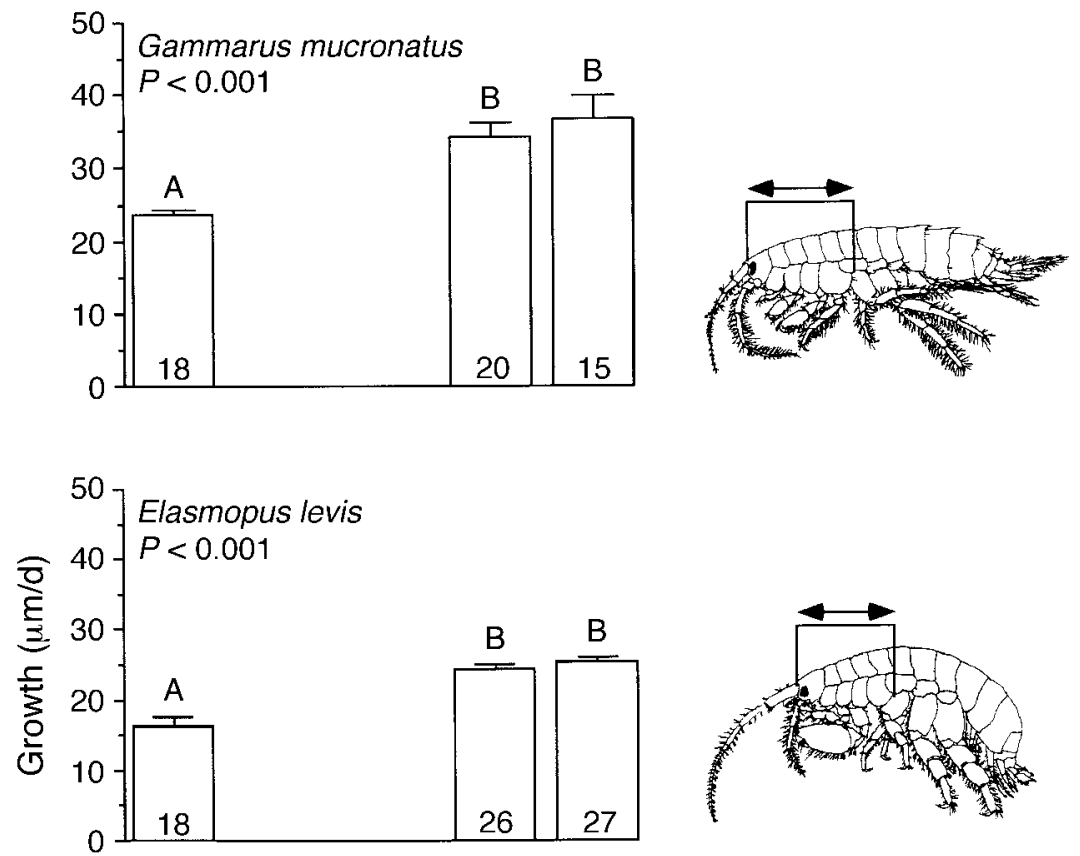

Ampithoe longimana
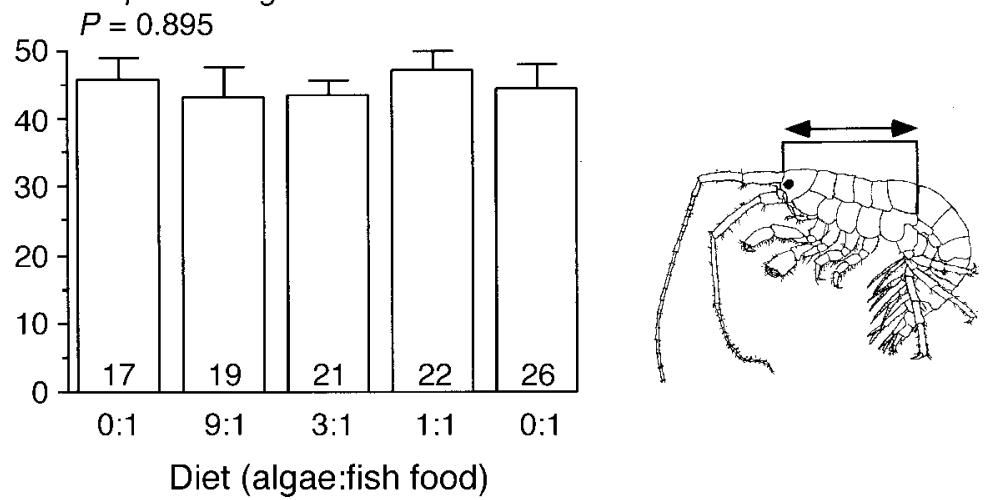

FIG. 5. Growth (mean $+1 \mathrm{SE}$ ) of amphipods on different diets. Sample size is at the base of each bar. Diets (on the $x$-axis) are given as ratios of algal food to fish food. Growth was measured under a dissection microscope as the change in length from the rostrum to the last large coxa (as indicated by the arrows in the drawings). Growth rates were determined by dividing this change by the number of days required to attain final size. The $P$ values and significant groupings are from ANOVA followed by Tukey's hsd tests. Different uppercase letters within a panel denote statistically significant differences between means.

\section{DisCUSSION}

The foods used in this study encompassed broad differences in food quality. A contrast of the algal-based vs. the fish-food-based diets shows a 21 -fold difference in protein, a threefold difference in nitrogen, and a twofold difference in carbon. These differences are within the range of nutritional values that would be encountered by mesoconsumers in the field. For example, protein content in seaweeds can be $<1 \%$, which is comparable to our lower quality algal food, whereas protein content of marine animals can be as high as $51 \%$, which is considerably higher than that of our highest quality diet (reviewed in Duffy and Paul [1992]). Thus, for marine mesoconsumers that ingest foods ranging from detritus, to plants, to animals, the 21 -fold difference in protein of the foods we used represents only a subset of the 64 -fold difference in protein these consumers can encounter in the field.

Although all consumers must choose among prey of differing nutritional value, these choices can be crucial for herbivores, because they rely on prey that are critically low in protein compared to what is needed for producing animal biomass (Mattson 1980, White 1993). In fact, the low nutritional quality of plant tissue 


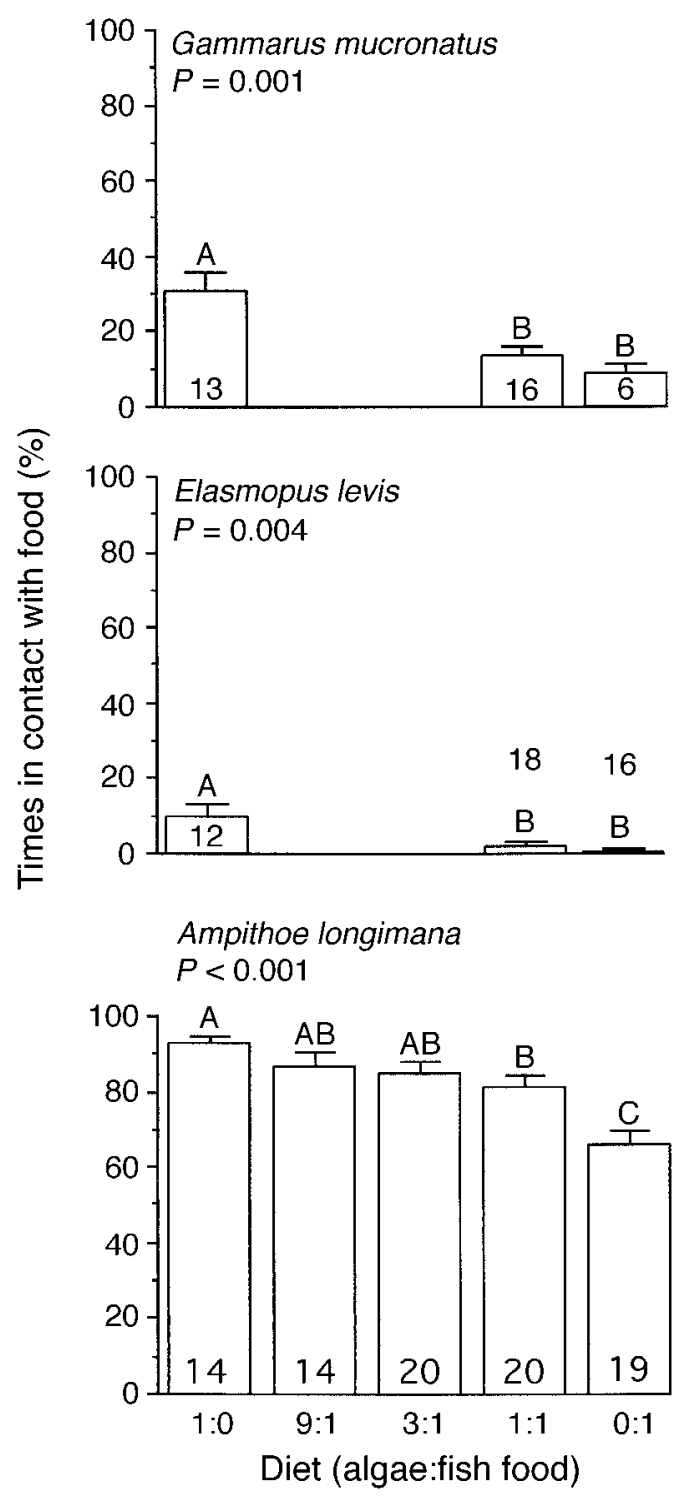

FIG. 6. Frequency at which amphipods were found in contact with food strips in the various treatments (mean $+1 \mathrm{SE}$ ). Observations were conducted as soon as the amphipods could be located with the naked eye. Sample size is given at the base (or on top) of each bar. The number of times an amphipod was found in direct contact with the food was converted to a percentage and analyzed by ANOVA or Kruskal-Wallis tests, followed by the appropriate post hoc tests. Observations were conducted once a day, at haphazardly chosen times. Only amphipods with $>10$ observations were included in the analyses. Within each panel, statistically significant $(P<$ 0.05 ) differences between means are indicated by different uppercase letters.

has been proposed as one of the principal barriers to the evolution of herbivory (Southwood 1973, Mattson 1980, Strong et al. 1984, Mitter et al. 1988, White 1993). Animals that do feed primarily on plants often show behavioral, morphological, and physiological adaptations that allow them to use nutritionally inferior
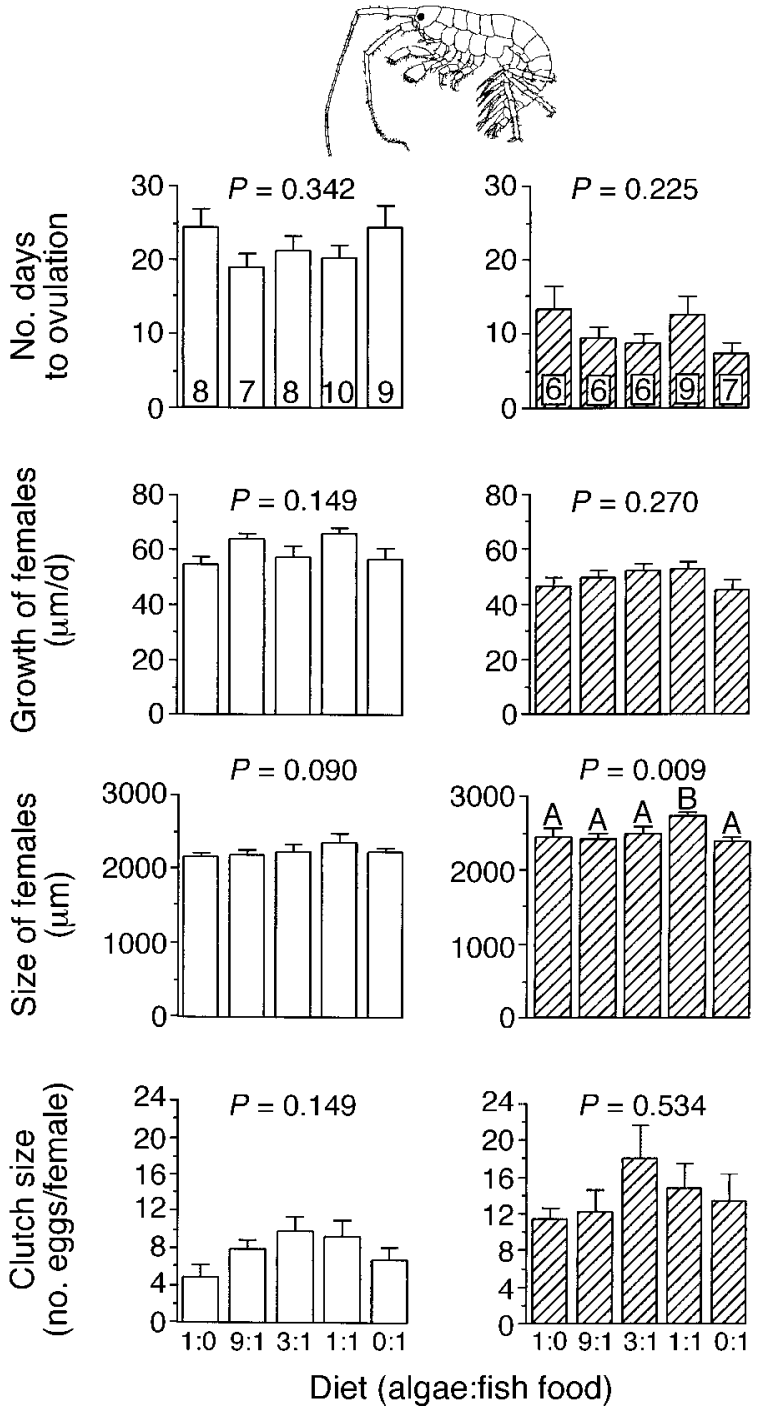

FIG. 7. Selected reproductive parameters measured for Ampithoe longimana females during two successive ovulations. Open bars indicate first ovulation, and hatched bars indicate second ovulation. $P$ values and significant groupings are from ANOVA followed by Tukey's hsd tests when necessary significant difference $(P<0.05)$ between means are indicated by different uppercase letters. The number of females in each treatment, for each ovulation, is given at the base of the bars on the top row of histograms. No surviving females of this species failed to ovulate twice. Bars represent means +1 SE.

foods more efficiently. As an example, microbial symbionts in herbivore guts enhance metabolism of lower quality foods (Mattson 1980, Martin 1987, Slansky and Rodriguez 1987, Barbosa et al. 1991, White 1993).

Low food value of plants can have considerable direct and indirect consequences for plants, herbivores, and the structure and function of communities and ecosystems. Examples include: (1) herbivores essentially starving in an abundance of low-quality food because, under some conditions, they simply cannot process 

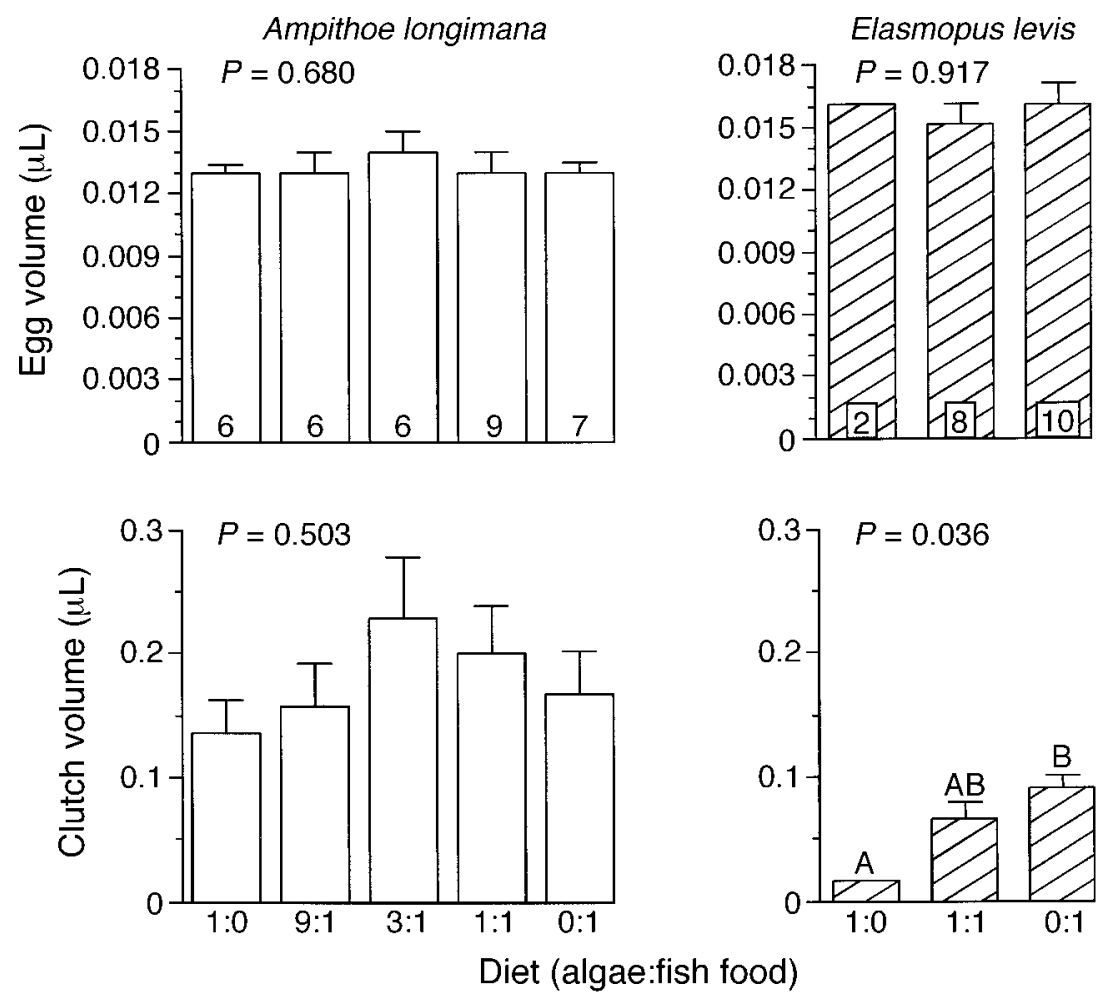

FIG. 8. Egg and clutch volumes for Ampithoe longimana and Elasmopus levis. These data correspond to the second ovulation for both species, when females were fixed and eggs measured. Note that egg volume for Elasmopus is larger than for Ampithoe. However, Elasmopus produced fewer eggs, resulting in a smaller clutch volume. Statistical analyses were by ANOVA followed by Tukey's hsd tests when necessary. Within a panel, statistically significant $(P<0.05)$ differences between means are indicated by different uppercase letters. Note that only two Elasmopus females reached a second ovulation in the algal-only (1:0) diet. Bars represent means +1 SE.

enough plant material to acquire adequate protein (White 1993); (2) herbivorous fishes consuming many times their daily energetic needs in order to acquire adequate nitrogen from seaweeds (Hatcher 1981, Horn 1989), thus producing dramatic effects on seaweeds, competitors of seaweeds, and coral reef communities in general (Hay 1991, Miller 1998); (3) herds of African ungulates being forced to migrate seasonally, when their compensatory feeding is unable to offset the declining nutritional value of their forage, thus affecting ecosystem processes over large spatial scales (Sinclair 1975, Sinclair and Norton-Griffiths 1979); and (4) phosphorous-limited phytoplankton being less digestible and more resistant to gut passage, thus reducing zooplankton fitness, and indirectly affecting zooplankton competition and secondary production in pelagic environments (van Donk and Hessen 1993, Sterner and Hessen 1994).

Critically low nutritive value has been hypothesized to be a form of plant resistance to natural enemies (Feeney 1976, Moran and Hamilton 1980, Price et al. 1980, White 1993, Augner 1995). However, some animals can behaviorally compensate for lower quality foods by increasing feeding rates (Simpson and Simpson 1990, Rueda et al. 1991, Slansky 1993), or actively choosing foods that balance nutritional requirements (Simpson and Simpson 1990, Pennings et al. 1993, Bernays, et al. 1994). Compensation can also be achieved by altering the rate of some physiological processes (Simpson and Simpson 1990, Targett and Targett 1990, Graça et al. 1993). For example, Graça et al. (1993) found that a freshwater species of Gammarus could successfully compensate for lower food quality by adjusting its respiration rate, rather than its ingestion rate. In contrast, Ampithoe longimana in our study adjusted its rate of consumption, consuming $3-70 \times$ more algalbased than fish-food-based diet when confined to single diets during our four-day feeding experiment (Fig. 3). Successfully compensating species like A. longimana limit the ability of low food quality to act as a defense, because the reduced value of the prey mandates that host-associated consumers eat more, rather than less, of the plant. Similar patterns have been noted in terrestrial systems (Price et al. 1980, Clancy and Price 1987, Leather and Walsh 1993; but see Benrey and Denno [1997]), and models assessing the ability of low food value to function as a prey defense note that conditions under which this strategy might aid the prey are limited (Moran and Hamilton 1980). However, if lower value plants are interspersed among more nutri- 


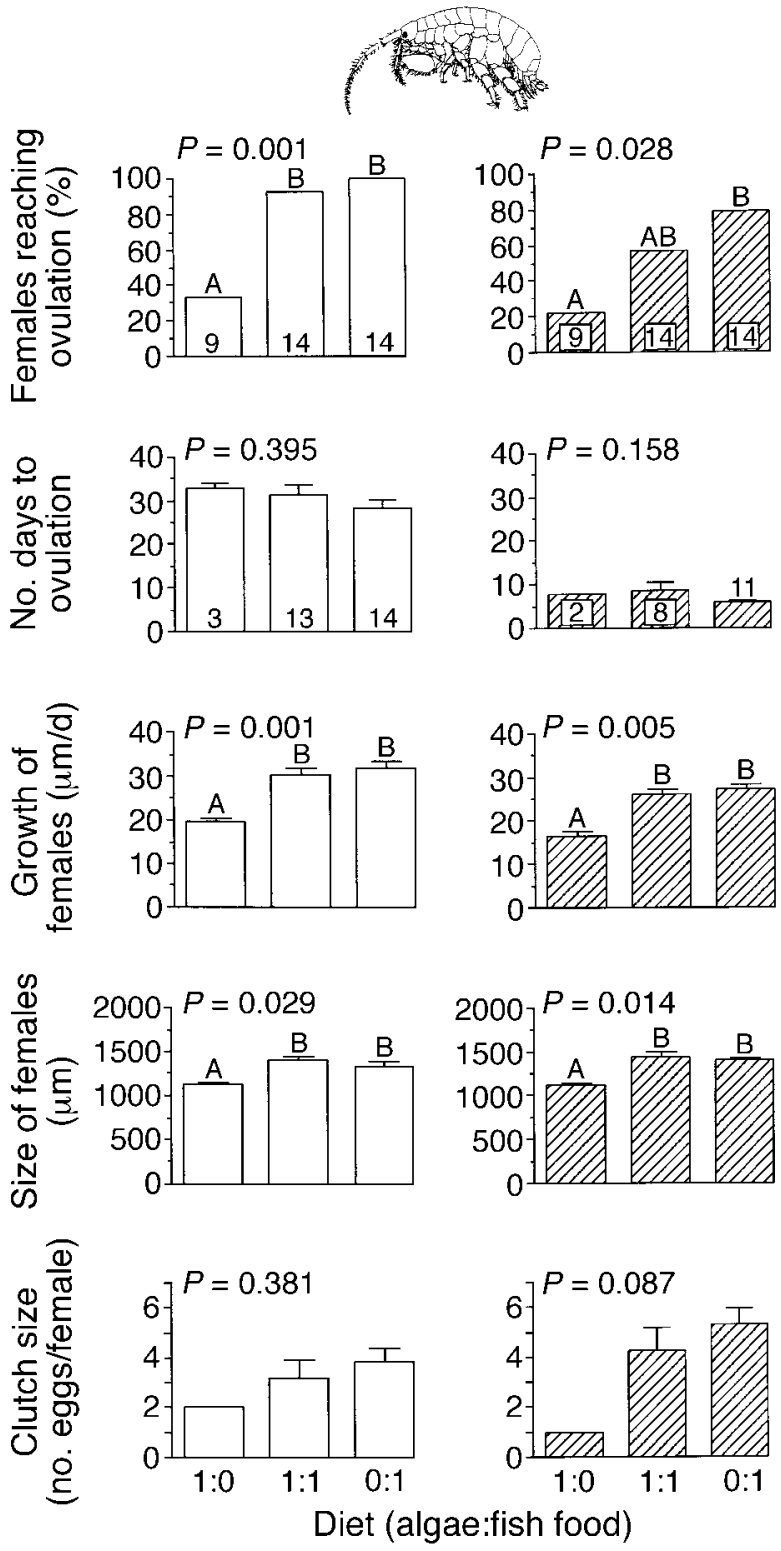

FIG. 9. Selected reproductive parameters measured for Elasmopus levis females during two successive ovulations. Open bars indicate first ovulation, and hatched bars indicate second ovulation. The top row of graphs shows the percentage of females reaching ovulation and was analyzed using $\chi^{2}$ tests It represents a frequency; thus, there are no error bars. The total number of females in each treatment is given at the base of the bars in the top row of histograms. For the remaining parameters measured, bars represent means $+1 \mathrm{SE}$, and the number of ovigerous females per treatment is given at the base of the bars on the second row of histograms of each column. Except for the graphs on the top row, $P$ values and significant groupings are from ANOVA followed by Tukey's hsd. Within a panel, statistically significant $(P<0.05)$ differences between means are indicated by different uppercase letters. Note that the number of ovulating females in the algalonly (1:0) diet was very low.
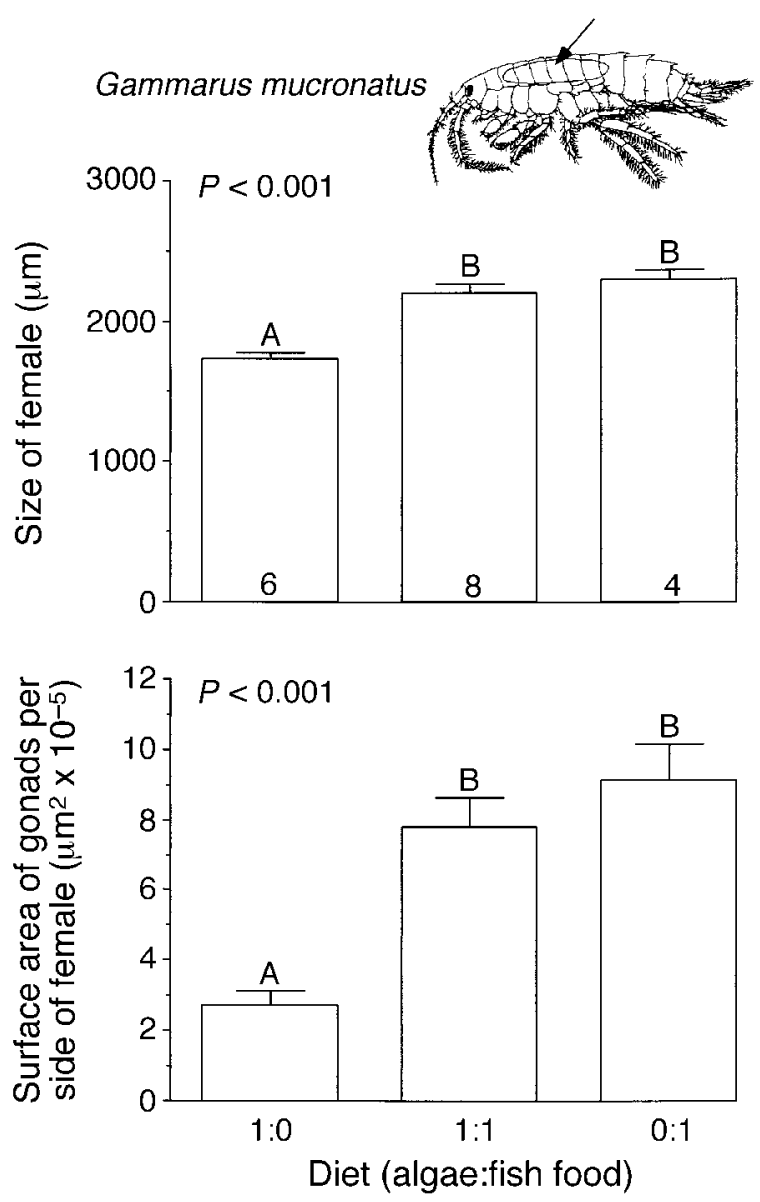

FIG. 10. Selected reproductive parameters measured in Gammarus mucronatus females. Females of this amphipod species failed to ovulate in any of the treatments. Reproductive potential was approximated by measuring the projected surface area of the gonads on each side of the female's body (as indicated by the arrow). The average surface area per side of the body is given on the bottom histogram. The length of the females was measured as indicated in Fig. 5. Statistical analyses were by ANOVA followed by Tukey's hsd tests. The number of females is indicated at the base of the treatment bars on the top histogram. Bars represent means +1 SE. Within each panel, statistically significant $(P<0.05)$ differences between means are indicated by different uppercase letters.

tious alternative hosts, then lower quality species or individuals could be avoided in favor of more attractive neighbors (Atsatt and O'Dowd 1976), provided that consumers are capable of adequate movement among plants.

There have been numerous investigations of compensatory feeding in insects and other terrestrial invertebrates, such as slugs. Most of these studies have manipulated diet quality by adding a diluting agent, such as water (Simpson and Simpson 1990, Rueda et al. 1991, Slansky 1993). Our study differs in that the concentration of food (i.e., dry mass per bite) was held constant across all diets. Therefore, compensatory 
feeding in these amphipods was a function of the identity, rather than density, of the foods used for making the artificial diets. Recognizing and responding to differences in prey nutrient content should be important for these mesoconsumers, because they commonly encounter and consume a wide variety of foods that have considerable nutritional disparity. The broad diversity of foods (e.g., detritus, seaweeds, and copepods) that are utilized by these amphipod species suggests that compensatory feeding could be important in maintaining populations during periods when, or in areas where, high-quality foods are unavailable.

Feeding behavior is often assumed to be adaptive, but this assumption is infrequently tested and sometimes false (Futuyma and Moreno 1988, Courtney and Kibota 1990, Kibota and Courtney 1991). We tested the assumption by asking whether long-term effects on fitness could explain the feeding preferences of three sympatric amphipods. In general, feeding preferences mirrored effects of diets on consumer fitness. Gammarus and Elasmopus showed a preference for the higher quality food (Fig. 2), and their growth and fecundity generally increased when they had access to higher quality food (Figs. 4, 5 and 8-10). For Gammarus, however, the high-quality food was associated with a decrease in survivorship (Fig. 4). We suspect that this result for Gammarus was an artifact, because this pattern was not observed when a similar experiment was run using the same foods (E. Cruz-Rivera and M. E. Hay, unpublished manuscript), but only after they were treated with organic solvents, which would kill most microbes. This suggests that the high-quality diet in our assay could have increased the establishment of microbes that negatively affected the survivorship of susceptible Gammarus individuals early in the experiment (days 1-16). Such an indirect effect is also suggested by the finding that surviving Gammarus grew larger and produced more gonads when feeding on this higher quality food. In contrast to patterns for Gammarus and Elasmopus, Ampithoe longimana did not discriminate among diets (Fig. 2), and its fitness did not vary across any of the diets tested (Figs. 4, 5, 7, and 8).

We measured fecundity in Gammarus mucronatus by quantifying the area of the gonads, because females in our treatments never ovulated. Gammarus mucronatus undergoes precopula before ovulating (Borowsky 1984). A male grabs a female with its gnathopods and the pair remains attached until the female molts. After molting, the female is inseminated and released. Amphipods were isolated as individuals in our treatments, keeping females from contact with males, which may explain why G. mucronatus females never produced eggs. It is plausible that the male stimulus is required to induce egg deposition in the brood pouch. Alternatively, our experiments may have not allowed enough time for the females to mature until the age of initial egg production. This was not explicitly tested, but field- collected ovigerous females were often of similar size or smaller than many of the females we obtained in our treatments after $42 \mathrm{~d}$ (E. Cruz-Rivera, personal observation).

In contrast with the differences in feeding choices among the three species, when confined with only one type of food, all three amphipods showed compensatory feeding on the lower quality diet (Fig. 3, Table 1) and spent more time in contact with this diet (Fig. 6). Despite this compensatory feeding, Gammarus mиcronatus and Elasmopus levis experienced decreased growth, reproductive output, and, for Elasmopus, survivorship on the low-quality food. In contrast, Ampithoe longimana survived, grew, and reproduced equally well across the entire range of foods we provided. $A$. longimana also differs from most co-occurring herbivores in being able to live on and consume brown algae that are chemically repugnant to other consumers (Hay et al. 1987, 1988, Duffy and Hay 1991b, 1994, Cronin and Hay $1996 a, b)$. This occurs although feeding by A. longimana can be deterred by secondary metabolites from these algae (Cronin and Hay 1996a, b). Thus, $A$. longimana seems to be unusually resistant to the negative effects of both low nutritional value and chemical defenses of its prey.

Ampithoe longimana shows strong feeding preferences when offered multiple species of algae (Hay et al. 1987, Duffy and Hay 1991b, 1994), however, neither protein nor nitrogen content of the algae correlate with feeding choices (Duffy and Hay 1991b). Similarly, A. longimana did not selectively consume high-quality foods in our experiments (Fig. 2). When A. longimana are grown on monospecific algal diets, there is a correlation between algal protein content and early survivorship of the juveniles (Duffy and Hay 1991b). However, once A. longimana survives this critical juvenile stage, growth, age at maturity, clutch size, and size of individual eggs does not vary as a function of algal species used as food (Duffy and Hay 1991b). This suggests that $A$. longimana may compensate for quality differences among natural algal foods, just as they do for the foods we made in this study.

The mechanism allowing Ampithoe, but not Gammarus or Elasmopus, to successfully substitute food quantity for food quality is unknown. However, because all three species demonstrated compensatory feeding, these interspecific differences may reflect physiological, rather than behavioral, constraints. The dramatic ability of A. longimana to substitute food quantity for quality may play an important role in allowing it to reduce its mobility and spend long periods associated with individual host plants; low rates of movement and selective association with hosts that are chemically repugnant to fishes provide the amphipod with a habitat that is relatively free from fish predation (Hay et al. 1987, Duffy and Hay 1991b, 1994). Minimizing movement by having the ability to live on, and often to feed from, a protective host appears to be an 
important component of the ecology and evolution of a variety of commensal relationships between mesoconsumers and hosts (Hay 1992, Stachowicz and Hay 1996, 1999a, b. Sotka et al. 1999).

In contrast to Ampithoe longimana, Gammarus mucronatus and Elasmopus levis appear to be more mobile (Nelson 1979a, Duffy and Hay 1994) and could not remain on, and feed from, low-quality foods for long periods without experiencing reduced fitness. Unlike A. longimana living on chemically defended seaweeds, both of these species experience large reductions in density when predatory fishes become common (Nelson $1979 a$, Duffy 1989, Duffy and Hay 1991b, 1994). Because both Gammarus and Elasmopus are unable to compensate completely for the low quality of algal foods, they would be less able to reduce predation risk by staying on individual seaweeds for extended periods. These patterns suggest that different mechanisms of dietary compensation select for, or are selected by, differences in consumer mobility. These patterns of mobility, in turn, could have profound consequences for the susceptibility of small consumers to predators. However, whether different compensatory mechanisms are a consequence of, or a constraint to, the evolution of feeding behavior remains unknown. Although the apparent relation between mesograzer mobility and compensatory feeding has been noted previously for insects (Bernays and Graham 1988, Bernays et al. 1994) and a small marine crab (Stachowicz and Hay 1996), the consequences of compensation for the fitness of these organisms remain unstudied. We present the connection between successful compensatory feeding and a sedentary lifestyle as a testable hypothesis that requires further evaluation.

More mobile consumers like Gammarus mucronatus and Elasmopus levis that experience lowered fitness when confined to algal diets could increase their fitness by consuming mixed diets of both plant and animal material, as occurs in many other animals that readily consume plants (Mattson 1980, White 1993, Kennish 1996). In our experiments, mixed diets containing different amounts of algae and fish food were used to mimic foods of intermediate quality. However, the commercial fish food is designed to offer a nutrientrich and balanced diet, and it contains both animal and vegetable matter. Therefore, we could not address how animal-derived food alone would affect these organisms. Our findings do show, however, that even when half of the diet consists of lower quality plant material (or more than half if the vegetable component of the fish food is considered), fitness of G. mucronatus and E. levis may not be adversely affected.

The large scope for compensation demonstrated by Ampithoe longimana appears unusual among mesoconsumers. Although some studies have suggested compensation to be important in the feeding biology of an isopod (Morán and Arrontes 1994), no studies on the long-term effects of diverse foods for amphi- pods, small aquatic detritivores, or other marine herbivores that spend a portion of their lives as mesograzers have documented the type of successful compensatory feeding we found for this species (Bärlocher and Kendrick 1975, Willoughby and Sutcliffe 1976, Vadas 1977, Kitting 1980, Larson et al. 1980, Nicotri 1980, Pomeroy and Levings 1980, Vasallo and Steele 1980, Sutcliffe et al. 1981, Robertson and Lucas 1983, Watanabe 1984, Poovachiranon et al. 1986, Pennings 1990, Paul and Pennings 1991, Trowbridge 1991, DeLong et al. 1993, Graça et al. 1993, Pennings et al. 1993, Bärlocher and Newell 1994, Pöckl 1995, Kennish 1996, Olivier et al. 1996, Kneib et al. 1997). For terrestrial systems, the only examples of compensatory feeding completely circumventing the negative effects of low food quality on fitness are found among insects (Simpson and Simpson 1990, Slansky 1993). It appears that numerous mesoconsumers will feed from a wide variety of foods, but that most will benefit significantly from selecting nutrient-rich foods, like animal tissue, or from mixing diets (e.g., Vasallo and Steele 1980, DeLong et al. 1993, Pennings et al. 1993, Kennish 1996).

Many previous investigations of plant-herbivore and predator-prey interactions have focused on how chemical, morphological, or structural defenses of the prey affect consumer-prey interactions, population and community structure, and the evolutionary patterns and processes affecting marine and terrestrial systems (for reviews, see Vermeij 1987, Duffy and Hay 1990, Harvell 1990, Fritz and Simms 1992, Paul 1992, Rosenthal and Berenbaum 1992, Hay 1996). Although the potential importance of prey nutritional value has been recognized (Mattson 1980, Lubchenco and Gaines 1981, Slansky and Rodriguez 1987, White 1993), fewer studies have explicitly focused on this aspect of prey-consumer interactions, especially in marine systems (Hay 1996). Understanding food utilization by animals requires that linkages between feeding behavior and fitness be determined. Few studies have directly measured the fitness-based consequences of diet selection or nutritional compensation. This study provides an initial step in understanding the connections between food quality, compensatory feeding, and fitness of marine mesograzers. It also suggests that marine mesograzers can differ considerably in their feeding habits and abilities, as has been demonstrated in other recent studies (Duffy 1990, Duffy and Hay 1991a, 1994, Brawley 1992, Stachowicz and Hay 1999a). The species-specific effects of marine mesograzers on their prey, and on marine communities in general, deserves additional attention, and small marine consumers should not continue to be pooled into one functional group whose members are assumed to have similar nutritional needs and feeding capabilities.

\section{ACKNOWLEDGMENTS}

We are grateful to Deetz Whichard and Stephan Bullard for assistance during the culturing experiments, and Debbie 
Daniel for processing the CHN analysis samples at East Carolina University. We thank W. Vader, and J. Holsinger for updating us in the current status of amphipod systematics, and F. Slansky, E. A. Bernays, M. Augner, J. E. Duffy, and J. D. Thomas for pointing out relevant literature (or lack thereof). Comments by C. H. Peterson, J. Pawlik, F. Micheli, R. Grosberg, and two anonymous reviewers greatly improved the manuscript. This work benefited from the support of a Ford Foundation Predoctoral Fellowship for Minority Students to E. Cruz-Rivera, and National Science Foundation (NSF) grants OCE 9202847 and 9529784 to M. E. Hay.

\section{Literature Cited}

Atsatt P. R., and D. J. O’Dowd. 1976 Plant defense guilds. Science 193:24-29.

Augner, M. 1995. Low nutritive quality as a plant defence: effects of herbivore-mediated interactions. Evolutionary Ecology 9:1-12.

Barbosa, P., V. A. Krischik, and C. G. Jones. 1991. Microbial mediation of plant-herbivore interactions. John Wiley and Sons, New York, New York, USA.

Bärlocher, F., and B. Kendrick. 1975. Assimilation efficiency of Gammarus pseudolimnaeus (Amphipoda) feeding on fungal mycelium and autumn-shed leaves. Oikos 26:55-59.

Bärlocher, F., and S. Y. Newell. 1994. Growth of the salt marsh periwinkle Littoraria irrorata on fungal and cordgrass diets. Marine Biology 118:109-114.

Beare, D. J., and P. G. Moore. 1997. The contribution of Amphipoda to the diet of certain inshore fish species in Kames Bay, Millport. Journal of the Marine Biological Association of the United Kingdom 77:907-910.

Bell, S. S. 1991. Amphipods as insect equivalents? an alternative view. Ecology 72:350-354.

Benrey, B., and R. F. Denno. 1997. The slow-growth-highmortality hypothesis: a test using the cabbage butterfly. Ecology 78:987-999.

Bernays, E. A., K. L. Bright, N. Gonzalez and J. Angel. 1994. Dietary mixing in a generalist herbivore: tests of two hypotheses. Ecology 75:1997-2006.

Bernays, E. A., and M. Graham. 1988. On the evolution of host specificity in phytophagous arthropods. Ecology 69 886-892.

Borowsky, B. 1984. The use of the male's gnathopods during precopulation in some gammaridean amphipods. Crustaceana 47:245-250.

Bousfield, E. L. 1973. Shallow water gammaridean Amphipoda of New England. Cornell University Press, Ithaca, New York, USA.

Bradford, M. M. 1976. A rapid and sensitive method for the quantification of microgram quantities of protein utilizing the principle of protein-dye binding. Analytical Biochemistry 72:248-254.

Brawley, S. H. 1992. Mesoherbivores. Pages 235-263 in D. M. John, S. J. Hawkins, and J. H. Price, editors. Plantanimal interactions in the marine benthos. Clarendon Press, Oxford, UK.

Brawley, S. H., and W. H. Adey. 1981. The effect of micrograzers on algal community structure in a coral reef microcosm. Marine Biology 61:167-177.

Carrasco, F. D., and D. F. Arcos. 1984. Life history of a coldtemperate population of the sublittoral amphipod Ampelisca araucana. Marine Ecology Progress Series 14:245-252.

Clancy, K. M., and P. W. Price. 1987. Rapid herbivore growth enhances enemy attack: sublethal plant defenses remain a paradox. Ecology 68:733-737.

Courtney, S. P., and T. T. Kibota. 1990. Mother doesn't know best: selection of hosts by ovipositing insects. Pages 161188 in E. A. Bernays, editor. Plant-insect relationships. Volume 2. CRC Press, Boca Raton, Florida, USA.

Cronin, G., and M. E. Hay. 1996a. Susceptibility to herbi- vores depends on recent history of both the plant and animal. Ecology 77:1531-1543.

Cronin, G., and M. E. Hay. 1996b. Induction of seaweed chemical defenses by amphipod grazing. Ecology 77:22872301.

Davis, E. M. 1988. Protein assays: a review of common techniques. American Biotechnology Laboratory 6:28-37.

Day, R. W., and G. P. Quinn. 1989. Comparisons of treatments after an analysis of variance in ecology. Ecological Monographs 59:433-463.

DeLong, M. D., R. B. Summers, and J. H. Thorp. 1993. Influence of food type on the growth of a riverine amphipod, Gammarus fasciatus. Canadian Journal of Fisheries and Aquatic Sciences 50:1891-1896.

Duffy, J. E. 1989. Ecology and evolution of herbivory by marine amphipods. Dissertation. University of North Carolina at Chapel Hill, Chapel Hill, North Carolina, USA.

Duffy, J. E. 1990. Amphipods on seaweeds: partners or pests? Oecologia 83:267-276.

Duffy, J. E., and M. E. Hay. 1990. Seaweed adaptations to herbivory. BioScience 40:368-375.

Duffy, J. E., and M. E. Hay. 1991a. Amphipods are not all created equal: a reply to Bell. Ecology 72:354-358.

Duffy, J. E., and M. E. Hay. 1991b Food and shelter as determinants of food choice by an herbivorous marine amphipod. Ecology 72:1286-1298.

Duffy, J. E., and M. E. Hay. 1994 Herbivore resistance to seaweed chemical defense: the roles of mobility and predation risk. Ecology 75:1304-1319.

Duffy, J. E., and V. J. Paul. 1992. Prey nutritional quality and the effectiveness of chemical defenses against tropical reef fishes. Oecologia 90:333-339.

Feeney, P. 1976. Plant apparency and chemical defense. Recent Advances in Phytochemistry 10:1-40.

Fox, R. S. 1980. Community biology of the amphipod crustaceans on Busycon egg strings. Thesis. University of North Carolina at Chapel Hill, Chapel Hill, North Carolina, USA.

Fredette, T. J., and R. J. Diaz. 1986. Life history of Gammarus mucronatus Say (Amphipoda: Gammaridae) in warm temperate estuarine habitats, York River, Virginia. Journal of Crustacean Biology 6:57-78.

Fritz, R. S., and E. L. Simms. 1992. Plant resistance to herbivores and pathogens: ecology, evolution, and genetics. University of Chicago Press, Chicago, Illinois, USA.

Futuyma, D. J., and G. Moreno. 1988. The evolution of ecological specialization. Annual Review of Ecology and Systematics 19:207-233.

Graça, M. A. S., L. Maltby, and P. Calow. 1993. Importance of fungi in the diet of Gammarus pulex and Asellus aquaticus. Oecologia 96:304-309.

Grebmeier, J. M., and N. M. Harrison. 1992. Seabird feeding on benthic amphipods facilitated by gray whale activity in the northern Bering Sea. Marine Ecology Progress Series 80:125-133.

Harvell, C. D. 1990. The ecology and evolution of inducible defenses. Quarterly Review of Biology 65:323-337.

Hatcher, B. G. 1981. The interaction between grazing organisms and the epilithic algal community of a coral reef: a quantitative assessment. Proceedings of the International Coral Reef Symposium, Fourth 2:515-524.

Hay, M. E. 1991. Fish-seaweed interactions on coral reefs: effects of herbivorous fishes and adaptations of their prey. Pages 96-119 in P. F. Sale, editor. The ecology of fishes on coral reefs. Academic Press, San Diego, California, USA.

Hay, M. E. 1992. The role of seaweed chemical defenses in the evolution of feeding specialization and in the mediation of complex interactions. Pages 93-118 in V. J. Paul, editor. Ecological roles for marine natural products. Comstock Press, Ithaca, New York, USA.

Hay, M. E. 1996. Marine chemical ecology: what is known and 
what is next? Journal of Experimental Marine Biology and Ecology 200:103-134.

Hay, M. E., J. E. Duffy, C. A. Pfister, and W. Fenical. 1987. Chemical defense against different marine herbivores: are amphipods insect equivalents? Ecology 68:1567-1580.

Hay, M. E., and W. Fenical. 1988. Marine plant-herbivore interactions: the ecology of chemical defense. Annual Review of Ecology and Systematics 19:111-145.

Hay, M. E., and W. Fenical. 1996. Chemical ecology and marine biodiversity: insights and products from the sea. Oceanography 9:10-20.

Hay, M. E., Q. E. Kappel, and W. Fenical. 1994 Synergisms in plant defenses against herbivores: interactions of chemistry, calcification, and plant quality. Ecology 75:1714-1726.

Hay, M. E., P. E. Renaud, and W. Fenical. 1988. Large mobile vs. small sedentary herbivores and their resistance to seaweed chemical defenses. Oecologia 75:246-252.

Hay, M. E., J. J. Stachowicz, E. Cruz-Rivera, S. Bullard, M. S. Deal, and N. Lindquist. 1998. Bioassays with marine and freshwater macroorganisms. Pages $39-141$ in K. F. Haynes and J. G. Millar, editors. Methods in chemical ecology. Volume 2. Bioassay methods. Chapman and Hall, New York, New York, USA.

Hay, M. E., and P. D. Steinberg. 1992. The chemical ecology of plant-herbivore interactions in marine vs. terrestria communities. Pages 372-408 in G. A. Rosenthal and M. R. Berenbaum, editors. Herbivores: their interactions with secondary plant metabolites. Volume II. Ecological and evolutionary processes. Academic Press, San Diego, California, USA.

Highsmith, R. C., and K. O. Coyle. 1990. High productivity of northern Bering Sea benthic amphipods. Nature 344: $862-864$.

Hines, A. H., A. M. Haddon, and L. A. Wiechert. 1990. Guild structure and foraging impact of blue crabs and epibenthic fish in a subestuary of Chesapeake Bay. Marine Ecology Progress Series 67:105-126.

Holmes, S. J. 1901. Observations on the habits and natural history of Ampithoe longimana Smith. Biological Bulletin of the Marine Biological Laboratory, Woods Hole 2:165193.

Horn, M. H. 1989. Biology of marine herbivorous fishes. Oceanography and Marine Biology Annual Review 27: 167-272.

Huang, C., and A. Sih. 1991. Experimental studies on direct and indirect interactions in a three trophic-level stream system. Oecologia 85:530-536.

Kennish, R. 1996. Diet composition influences the fitness of the herbivorous crab Grapsus albolineatus. Oecologia 105 22-29.

Kibota, T. T., and S. P. Courtney. 1991. Jack of one trade, master of none: host choice by Drosophila magnaquinaria. Oecologia 86:251-260.

Kitting, C. L. 1980. Herbivore-plant interactions of individual limpets maintaining a mixed diet of intertidal marine algae. Ecological Monographs 50:527-550.

Kneib, R. T., S. Y. Newell, and E. T. Hermeno. 1997. Survival, growth, and reproduction of the salt-marsh amphipod Uhlorchestia spartinophila reared on natural diets of senescent and dead Spartina alterniflora leaves. Marine Biology 128:423-431.

Larson, B. R., R. L. Vadas, and M. Kesser. 1980. Feeding and nutritional ecology of the sea urchin Strongylocentrotus drobachiensis in Maine, USA. Marine Biology 59:49-62.

Leather, S. R., and P. J. Walsh. 1993. Sub-lethal plant defences: the paradox remains. Oecologia 93:153-155.

Lewis, F. G., III. 1984. Distribution of macrobenthic crustaceans associated with Thalassia, Halodule, and bare sand substrata. Marine Ecology Progress Series 19:101-113.

Lindquist, N., and M. E. Hay. 1995. Can small rare prey be chemically defended? The case for marine larvae. Ecology 76:1347-1358.

Lubchenco, J., and S. D. Gaines. 1981. A unified approach to marine plant-hervibore interactions. I. Populations and communities. Annual Review of Ecology and Systematics 12:405-437.

Martin, M. M. 1987. Invertebrate-microbial interactions: ingested fungal enzymes in arthropod biology. Comstock Publishing Associates, Cornell University Press, Ithaca, New York, USA.

Mattson, W. J., Jr. 1980. Herbivory in relation to plant nitrogen content. Annual Review of Ecology and Systematics 11:119-161.

Miller, M. W. 1998. Coral/seaweed competition and the control of reef community structure within and between latitudes. Oceanography Marine Biology Annual Review 36: 65-96.

Mitter, C., B. Farrell, and B. Wiegmann. 1988. The phylogenetic study of adaptive zones: has phytophagy promoted insect diversification? American Naturalist 132:107-128.

Morán, J. A. G., and J. Arrontes. 1994. Factors affecting food preference in a widespread intertidal isopod. Journal of Experimental Marine Biology and Ecology 182:111121.

Moran, N., and W. D. Hamilton. 1980. Low nutritive quality as a defense against herbivores. Journal of Theoretical Biology 86:247-254.

Moreno, C. A., and H. F. Jara. 1984. Ecological studies on fish fauna associated with Macrocystys pyrifera belts in the south of Fueguian Islands, Chile. Marine Ecology Progress Series 15:99-107.

Nelson, W. G. 1979a. Experimental studies of selective predation on amphipods: consequences for amphipod distribution and abundance. Journal of Experimental Marine Biology and Ecology 38:225-245.

Nelson, W. G. 1979b. An analysis of structural pattern in an eelgrass (Zostera marina L.) amphipod community. Journal of Experimental Marine Biology Ecology 39:231-264.

Nicotri, M. E. 1980. Factors involved in herbivore food preference. Journal of Experimental Marine Biology and Ecology 42:13-26.

Olivier, M., G. Desrosiers, A. Caron, and C. Retière. 1996. Juvenile growth of the polychaete Nereis virens feeding on a range of marine vascular and macroalgal plant sources. Marine Biology 125:693-699.

Paine, R. T. 1992. Food-web analysis through field measurement of per capita interaction strength. Nature 355:73-75.

Paul, V. J., editor. 1992. Ecological roles of marine natural products. Cornell University Press, Ithaca, New York, USA.

Paul, V. J., and S. C. Pennings. 1991. Diet-derived chemical defenses in the sea hare Stylocheilus longicauda (Quoy et Gaimard 1824). Journal of Experimental Marine Biology and Ecology 151:227-243.

Pawlik, J. 1993. Marine invertebrate chemical defenses. Chemical Reviews 93:1911-1922.

Pennings, S. C. 1990. Multiple factors promoting narrow host range in the sea hare, Aplysia californica. Oecologia 82:192-200.

Pennings, S. C., T. N. Masatomo, and V. J. Paul. 1993. Selectivity and growth of the generalist herbivore Dolabella auricularia feeding upon complementary resources. Ecology 74:879-890.

Pöckl, M. 1995. Laboratory studies on growth, feeding, moulting and mortality in the freshwater amphipods Gammarus fossarum and G. roeseli. Archiv für Hydrobiologie 134:223-253.

Pomeroy, W. M., and C. D. Levings. 1980. Association and feeding relationships between Eogammarus confervicolus (Amphipoda, Gammaridae) and benthic algae on the Stur- 
geon and Roberts Banks, Fraser River Estuary. Canadian Journal of Fisheries and Aquatic Sciences 37:1-10.

Poovachiranon, S., K. Boto, and N. Duke. 1986. Food preference studies and ingestion rate measurements of the mangrove amphipod Parahyale hawayensis (Dana). Journal of Experimental Marine Biology and Ecology 98:129-140.

Posey, M. H., and A. H. Hines. 1991. Complex predatorprey interactions within an estuarine benthic community. Ecology 72:2155-2169.

Price, P. W., C. E. Bouton, P. Gross, B. A. McPheron, J. N. Thompson, and A. E. Weiss. 1980. Interactions among three trophic levels: influence of plants on interactions between insect herbivores and natural enemies. Annual Review of Ecology and Systematics 11:41-65.

Real, L., and T. Caraco. 1986. Risk and foraging in stochastic environments. Annual Review of Ecology and Systematics 17:371-390.

Robertson, A. I., and J. S. Lucas. 1983. Food choice, feeding rates, and the turnover of macrophyte biomass by a surfzone inhabiting amphipod. Journal of Experimental Marine Biology and Ecology 72:99-124.

Rosenthal, G. A., and M. R. Berenbaum, editors. 1992. Herbivores: their interactions with secondary plant metabolites. Volume II. Ecological and evolutionary processes. Academic Press, San Diego, California, USA.

Rueda, A. A., F. Slansky, Jr., and G. S. Wheeler 1991. Compensatory response of the slug Sarasinula plebeia to dietary dilution. Oecologia 88:181-188.

Sanders, H. L., E. M. Goudsmit, E. L. Mills, and G. E. Hampson. 1962. A study of the intertidal fauna of Barnstable Harbor, Massachusetts. Limnology and Oceanography 7: 63-79.

Sarvala, J., and A. Uitto. 1991. Production of the benthic amphipods Pontoporeia affinis and P. femorata in a Baltic archipielago. Ophelia 34:71-90.

Shaffer, J. A., D. C. Doty, R. M. Buckley, and J. E. West. 1995. Crustacean community composition and trophic use of the drift vegetation habitat by juvenile splitnose rockfish Sebastes diploproa. Marine Ecology Progress Series 123 13-21.

Sih, A. 1987. Predators and prey lifestyles: an evolutionary and ecological overview. Pages 203-224 in W. C. Kerfoot and A. Sih, editors. Predation: direct and indirect impacts on aquatic communities. University Press of New England, Hanover, New Hampshire, USA.

Simpson, S. J., and C. L. Simpson. 1990. The mechanisms of nutritional compensation by phytophagous insects. Pages 111-160 in E. A. Bernays, editor. Insect-plant interactions. Volume 2. CRC Press, Boca Raton, Florida, USA.

Sinclair, A. R. E. 1975. The resource limitation of trophic levels in tropical grassland ecosystems. Journal of Animal Ecology 44:497-520.

Sinclair, A. R. E., and M. Norton-Griffiths. 1979. Serengeti: dynamics of an ecosystem. University of Chicago Press, Chicago, Illinois, USA.

Slansky, F., Jr. 1993. Nutritional ecology: the fundamental quest for nutrients. Pages 29-91 in N. E. Stamp and T. M. Casey, editors. Caterpillars: ecological and evolutionary constraints on foraging. Chapman and Hall, New York, New York, USA.

Slansky, F., Jr., and J. G. Rodriguez, editors. 1987. Nutritional ecology of insects, mites, spiders, and related invertebrates. John Wiley and Sons, New York, New York, USA.

Slansky, F., Jr., and J. M. Scriber. 1985. Food consumption and utilization. Pages 87-163 in G. A. Kerkut and L. I. Gilbert, editors. Comprehensive insect physiology, biochemistry, and pharmacology. Volume 4. Pergamon Press, Oxford, UK.

Sotka, E. E., M. E. Hay, and J. D. Thomas. 1999. Hostplant specialization by a non-herbivorous amphipod: ad- vantages for the amphipod and costs for the seaweed. Oecologia 118:471-482.

Southwood, T. R. E. 1973. The insect/plant relationshipan evolutionary perspective. Symposia of the Royal Entomological Society of London 6:3-30.

Stachowicz, J. J., and M. E. Hay. 1996 Facultative mutualism between an herbivorous crab and a coralline alga: advantages of eating noxious seaweeds. Oecologia 105:377-387.

Stachowicz, J. J., and M. E. Hay. 1999a. Reducing predation through chemically-mediated camouflage: indirect effects of plant defenses on herbivores. Ecology 80:495-509.

Stachowicz, J. J., and M. E. Hay. 1999b. Mutualism and coral persistence: the role of herbivore resistance to chemical defense. Ecology, 80:2085-2101.

Stephens, D. W., and J. R. Krebs. 1986. Foraging theory. Princeton University Press, Princeton, New Jersey, USA.

Sterner, R. W., and D. O. Hessen. 1994. Algal nutrient limitation and the nutrition of aquatic herbivores. Annual Review of Ecology and Systematics 25:1-29.

Stockhoff, B. A. 1993. Diet heterogeneity: implications for growth of a generalist herbivore, the gypsy moth. Ecology 74:1939-1949.

Stoner, A. W. 1979. Species specific predation on amphipod crustacea by the pinfish Lagodon rhomboides: mediation by macrophyte standing crop. Marine Biology 55:201-207.

Strong, D. R., J. H. Lawton, and R. Southwood. 1984. Insects on plants. Harvard University Press, Cambridge, Massachusetts, USA.

Sutcliffe, D. W., T. R. Carrick, and L. G. Willoughby. 1981. Effects of diet, body size, age and temperature on growth rates in the amphipod Gammarus pulex. Freshwater Biology 11:183-214.

Targett, T. E., and N. M. Targett. 1990. Energetics of food selection by the herbivorous parrotfish Sparisoma radians: roles of assimilation efficiency, gut evacuation rate, and algal secondary metabolites. Marine Ecology Progress Series 66:13-21.

Trowbridge, C. D. 1991. Diet specialization limits herbivorous sea slug's capacity to switch among food species. Ecology 72:1880-1888.

Vadas, R. L. 1977. Preferential feeding: an optimization strategy in sea urchins. Ecological Monographs 47:337371.

van Donk, E., and D. O. Hessen. 1993. Grazing resistance in nutrient-stressed phytoplankton. Oecologia 93:508-511.

Van Soest, P. 1994. Nutritional ecology of the ruminant. Cornell University Press, Ithaca, New York, USA.

Vasallo, L., and D. H. Steele. 1980. Survival and growth of young Gammarus lawrencianus Bousfield, 1956, on different diets. Crustaceana, supplement 6:118-125.

Vermeij, G. J. 1987. Evolution and escalation: and ecological history of life. Princeton University Press, Princeton, New Jersey, USA.

Watanabe, J. M. 1984. Food preference, food quality, and diets of three herbivorous gastropods (Trochidae: Tegula) in a temperate kelp forest habitat. Oecologia 62:47-52.

White, T. C. R. 1993. The inadequate environment: nitrogen and the abundance of animals. Springer-Verlag, New York, New York, USA.

Widdowson, E. M., and J. C. Mathers. 1992. The contribution of nutrition to human and animal health. Cambridge University Press, Cambridge, UK.

Willoughby, L. G., and D. W. Sutcliffe. 1976. Experiments on feeding and growth of the amphipod Gammarus pulex (L.) related to its distribution in the River Duddon. Freshwater Biology 6:577-586.

Zar, J. H. 1984. Biostatistical analysis. Prentice-Hall, Englewood Cliffs, New Jersey, USA.

Zimmerman, R., R. Gibson, and J. Harrington. 1979. Herbivory and detritivory among gammaridean amphipods from a Florida seagrass community. Marine Biology 54: $41-47$. 